\title{
Kristaps Atstupens
}

\section{The role of laparoscopic intraoperative ultrasonography in patients with suspected choledocholithiasis}

Summary of the Doctoral thesis for obtaining a doctoral degree (Ph.D.)

Sector - Clinical Medicine Sub-sector - Surgery 


\section{RĪGA STRADIN̦Š UNIVERSITY}

Kristaps Atstupens

ORCID 0000-0001-9363-6195

\section{The role of laparoscopic intraoperative ultrasonography in patients with suspected choledocholithiasis}

Summary of the Doctoral thesis for obtaining a doctoral degree (Ph.D.)

Sector - Clinical Medicine

Sub-Sector - Surgery

Rīga, 2020 
The Doctoral thesis was carried out at Riga East Clinical University Hospital, Department of General and Emergency Surgery

Scientific supervisors:

Ph.D., Professor Guntars Pupelis, Rīga Stradiņš University, Department of Surgery, Latvia

Ph.D., Associate Professor Haralds Plaudis, Rīga Stradin̄š University, Department of Surgery, Latvia

Official reviewers:

Ph.D., Associate Professor Artūrs Ozoliṇ̌š, Rīga Stradiņš University, Department of Surgery, Latvia

Ph.D., Associate Professor Igors Ivanovs, University of Latvia, Faculty of Medicine

Ph.D., Professor Žilvinas Dambrauskas, Lithuanian University of Health Sciences, Faculty of Medicine, Department of Surgery

Defence of the Doctoral thesis will take place at the public session of the Doctoral Council of Clinical Medicine on 1 July 2020 at 13.00 in Hippocrates Lecture Theatre, 16 Dzirciema Street, Rīga Stradinš University.

The Doctoral thesis is available in the RSU library and at RSU webpage: www.rsu.lv

Secretary of the Doctoral Council:

Ph.D., Associate Professor Arvīds Irmejs 


\section{TABLE OF CONTENTS}

ABBREVIATONS

1. INTRODUCTION 7

1.1. Topicality of the Study

1.2. Scientific Novelty of the Study 10

1.3. Aim of the Study 11

1.4. Tasks of the Research 11

1.5. Hypothesis of the Study 12

1.6. Practical Value of the Study 12

2. MATERIALS AND METHODS 13

2.1. Inclusion Criteria 13

2.2. Exclusion Criteria 13

2.3. Population of the Study Groups 14

2.4. Data Collection $\quad 14$

2.5. Diagnostics and Treatment at the Time of Admission 14

2.6. Diagnostics and Treatment in the Department of Surgery 15

2.7. Surgery (Laparoscopy) 16

2.7.1. Intraoperative Ultrasonography 16

2.7.2. Laparoscopic Common Bile Duct Exploration 22

2.8. Statistical Analysis of the Data 25

2.9. Decision of the Ethics Committee 25

3. RESULTS 26

3.1. Structure and Demographics of Patients 26

3.2. Distribution of Patient Groups 26

3.3. Comparison of Groups 26

3.4. Characteristics of Trans-Abdominal Ultrasonography 28

3.4.1. Analysis of the Bile Duct Size on Trans-Abdominal Ultrasonography in Groups 28

3.4.2. Diagnosis of Choledocholithiasis on Trans-Abdominal Ultrasonography in Groups 29

3.5. Characteristics of Magnetic Resonance CholangioPancreatography Finding

3.5.1. Analysis of the Bile Duct Size on Magnetic Resonance Cholangio-Pancreatography in Groups

3.5.2. Magnetic Resonance Cholangio-Pancreatography

Finding Controlled by Intraoperative Ultrasonography

3.5.3. Diagnostic Value of Magnetic Resonance Cholangio-

Pancreatography in the Detection of Choledocholithiasis $\quad 33$

3.6. Characteristics of the Intraoperative Ultrasonography Finding 35 
3.6.1. Analysis of the Bile Duct Size on Intraoperative Ultrasonography in Groups

3.6.2. Diagnosis of Choledocholithiasis in Groups

3.7. Analysis of the Median Size of Stones on Magnetic

Resonance Cholangio-Pancreatography and Intraoperative Ultrasonography

3.8. Diagnostic Value of Intraoperative Ultrasonography and 38

Magnetic Resonance Cholangio-Pancreatography in Low, 38

Intermediate and High Risk Patients of Choledocholithiasis 38

3.9. Analysis of the Duration of Surgery in Groups 39

3.10. Analysis of the Duration of Hospitalisation $\quad 40$

3.11. Assessment of Complications 41

4. DISCUSSION 42

CONCLUSIONS 49

PRACTICAL RECOMMENDATIONS 51

BIBLIOGRAPHY 52

PUBLICATIONS AND PRESENTATIONS 56 


\section{ABBREVIATONS}

ABP

ALT

ASA score

AST

CBD

CNS

CRP

EP

ERCP

EUS

GGT

INR

IOC

IOUS

Leu

LCBDE

MODS

MRCP

REUH

SD

AF

SIRS

TAUS

GD acute biliary pancreatitis

alanine amino-transferase

American Society of Anaesthesiologists Physical Status

aspartate amino-transferase

common bile duct

central nervous system

C-reactive protein

endoscopic papillotomy

endoscopic retrograde cholangio-pancreatography

endoscopic ultrasound

gamma glutamyl transferase

international normalized ratio

intraoperative cholangiography

intraoperative ultrasonography

leukocytes

laparoscopic common bile duct exploration

multi-organ dysfunction syndrome

magnetic resonance cholangio-pancreatography

Riga East University Hospital

standard deviation

alkaline phosphatase

systemic inflammatory response syndrome

trans-abdominal ultrasonography

gallstone disease 


\begin{tabular}{|l|l|l|}
\hline Abbreviations & \multicolumn{1}{|c|}{ Latin } & \multicolumn{1}{c|}{ English } \\
\hline- & fundus (vesicae felleae) & fundus of the gallbladder \\
\hline AC & arteria cystica & gallbladder artery \\
\hline AHC & arteria hepatica communis & common hepatic artery \\
\hline AHD & arteria hepatica dextra & right hepatic artery \\
\hline AHDa & $\begin{array}{l}\text { arteria hepatica dextra } \\
\text { accesoria }\end{array}$ & $\begin{array}{l}\text { accessory right hepatic } \\
\text { artery }\end{array}$ \\
\hline AHP & arteria hepatica propria & proper hepatic artery \\
\hline AHS & arteria hepatica sinistra & left hepatic artery \\
\hline DC & ductus cysticus & cystic duct \\
\hline DC & ductus choledochus & common bile duct \\
\hline DHC & ductus hepaticus communis & common hepatic duct \\
\hline EP & epigastrium proprium & proper epigastric region \\
\hline LHD & $\begin{array}{l}\text { ligamentum hepato- } \\
\text { duodenale }\end{array}$ & hepato-duodenal ligament \\
\hline PV & papilla Vateri & duodenal papilla \\
\hline VP & vena porta & portal vein \\
\hline
\end{tabular}




\section{INTRODUCTION}

\subsection{Topicality of the Study}

Despite the wide range of diagnostic modalities that have appeared in medicine during the last decades, a timely diagnosis and a successful treatment of complicated gallstone disease remain major challenges.

The incidence of gallstone disease is on the rise, reaching $5.9 \%$ to 21.9 $\%$ in the common population in socially and economically developed countries, such as Norway and Germany (Aerts and Penninckx, 2003). 1.1 million cholecystectomies are performed every year in European countries due to gallstone disease (Borzellino and Cordiano, 2008), which is clearly associated with huge costs. Cholecystectomy is also one of the most common surgical operations in Latvia, and the number has not decreased significantly over the last years: 2699 operations in 2012, 3655 in 2013, 3657 in 2014, 3738 in 2015, 3723 in 2016, and 3680 cholecystectomies in 2017 (Latvian Association of Surgeons, 2018). Due to the increasing incidence of gallstone disease and the increasing number of operations, the incidence of choledocholithiasis is increasing secondary to both increased incidence of the disease and overlooked gallstones in the common bile duct during cholecystectomy. The available data suggest that choledocholithiasis is present in $11 \%$ to $21 \%$ cases during cholecystectomy (Costi et al., 2014). A similar probability of choledocholithiasis (8-20\%) has also been reported in the overall population in patients with symptomatic gallstone disease (Bencini et al., 2014). An asymptomatic group of patients with choledocholithiasis is also important, accounting for about half of this complicated form of gallstone disease (Sarli et al., 2000).

Potentially life-threating complications, such as acute biliary pancreatitis, acute cholangitis, liver abscesses often combined with mechanical 
jaundice, may occur in patients with choledocholithiasis; in complicated cases, they may cause a progressing biliary sepsis. These patients have a high risk of developing multi-organ dysfunction syndrome and septic shock, so the treatment of these pathologies is often time-consuming, complicated and multidisciplinary, involving not only surgeons, but also intensive care and sepsis specialists, gastroenterologists, invasive radiologists, endoscopists, etc. These facts highlight the need for additional examination of all patients with suspected bile duct stones, as well as for using the most effective treatment during the time of single hospitalisation. This would help to reduce the frequency of complications, mortality and costs.

The diagnosis of choledocholithiasis is based on the history of the disease, evaluation of clinical symptoms and signs in the context of laboratory data. Additionally, imaging is a very important and crucial aspect.

One of the latest algorithms for the diagnosis and treatment tactics of choledocholithiasis has been recommended by the American Society for Gastrointestinal Endoscopy (ASGE) published in the 2010 guidelines. The recommendations suggest three categories of risk of choledocholithiasis: low (<10\%), medium (10-50\%) and high (> 50\%) (Maple et al., 2010), and recommend the appropriate tactics in each category. However, the latest published data indicate some critical points of the ASGE guidelines and recommend finding alternative criteria to reduce unnecessary endoscopic retrograde cholangio-pancreatographies (ERCP) (Suarez et al., 2016; MonrealRobles and Gonzalezs-Gonzalez, 2016; Narvaez-Rivera et al., 2016).

There are two main principles of managing patients with suspected choledocholithiasis. The first is a one-step approach, based on bile duct imaging and clearance (if necessary) during laparoscopic cholecystectomy. The other one is a two-step approach that provides accurate preoperative diagnosis of choledocholithiasis (realised by magnetic resonance cholagiopancreatography, MRCP or endoscopic ultrasonography, EUS) followed by 
ERCP in case of choledocholithiasis. Laparoscopic cholecystectomy is postponed to the second stage of this approach.

Considering the fact that there is no consensus for the management of bile duct stones in the published data, it can be concluded that the diagnostic and treatment strategy of choledocholithiasis is mainly determined by the availability of equipment and the experience of staff in a particular medical facility, providing patient safety.

Trans-abdominal ultrasonography (TAUS) has an extremely important role in diagnosis of choledocholithiasis. The method is highly sensitive (55-91\%) in recognition of the indirect signs of bile duct stones - dilatation of the common bile duct and intrahepatic bile ducts (Liu et al., 2001), but also accurate (sensitivity $96 \%$ ) in the recognition of gallstone disease (Stott et al., 1991). However, an accurate diagnosis of choledocholithiasis is unsatisfactory with TAUS.

EUS is very informative, but due to its limited availability and high expenses, a less invasive alternative like MRCP is more practical.

ERCP is an invasive method and associated with a risk of potentially life-threatening complications, such as post-ERCP pancreatitis, bleeding, duodenal or bile duct perforation, cholecystitis, etc. Mortality after ERCP is $>0.5 \%$, mainly due to papillotomy during the procedure (Ong et al., 2005), so nowadays ERCP is recommended as a therapeutic option only for patients with a proven diagnosis.

MRCP is an accurate and non-invasive diagnostic method of bile ducts and the pancreatic duct and in most reports is recommended as the method of choice in the case of choledocholithiasis (Chen et al., 2015). According to various authors, the sensitivity and specificity of MRCP is high $-81 \%$ to 100 $\%$ and $92 \%$ to $100 \%$, respectively (Hallal et al., 2005). However, there are also some limitations. They include a reduced availability in the condition of a high flow of patients with gallstone disease, a lower diagnostic accuracy if 
stones in the bile duct are smaller than $5 \mathrm{~mm}$, especially in the case of biliary pancreatitis (Costi et al., 2014), as well as individual patient restrictions (claustrophobia, metallic implants, etc.).

Intraoperative imaging of bile ducts is mainly provided by two methods: intraoperative cholangiography (IOC) and intraoperative ultrasonography (IOUS). In cases of proved choledocholithiasis, laparoscopic common bile duct exploration (LCBDE) follows, which is a challenge for surgeons due to the need for advanced skills in laparoscopic surgery and specific equipment. LCBDE is approved as an effective, inexpensive and safe method with a low risk of complications and residual stones $-9.5 \%$ and $2.7 \%$, respectively (Riciardi et al., 2003). Compared to ERCP, LCBDE is an equally effective method for bile duct sanation (Nathanson et al., 2005; Dasari et al., 2013). IOUS and IOC are comparable, highly informative intraoperative diagnostic methods for choledocholithiasis, but due to the reduced invasiveness, and a shorter time for imaging and ionizing radiation, IOUS has several advantages over IOC (Hublet et al., 2009; Aziz et al., 2014).

Based on the above-mentioned facts, it can be concluded that the use of IOUS in the diagnosis of choledocholithiasis allows minimising expensive and time-consuming examinations in preoperative period and improving the diagnostic quality. That reduces the duration of hospitalisation, risk of complications and ensures a faster recovery.

\subsection{Scientific Novelty of the Study}

Specific intraoperative imaging (intraoperative ultrasonography) is performed for the first time in all patients with suspected choledocholithiasis and the data is compared with preoperative MRCP. 


\subsection{Aim of the Study}

The aim of the study is to find out the accuracy of IOUS in the diagnosis of choledocholithiasis, and to compare it with the data and diagnostic accuracy of preoperative TAUS and MRCP.

\subsection{Tasks of the Research}

1. To create a database for the evaluation of treatment results of the patient cohort with gallstone disease and suspected choledocholithiasis who undergo laparoscopic cholecystectomy and IOUS. For the assessment of the results, patients will be allocated in two groups:

- IOUS verified choledocholithiasis - standard laboratory + TAUS + MRCP;

- IOUS non-verified choledocholithiasis - standard laboratory + TAUS + MRCP.

The demographical data, ASA* score, preoperative laboratory, clinical and imaging data will be analyzed statistically.

2. To compare TAUS and MRCP data correlation with IOUS data (bile duct size, choledocholithiasis, size of the stones) as well as the diagnostic value of TAUS, MRCP and IOUS in the recognition of choledocholithiasis.

3. To compare MRCP and IOUS data in low, medium and high risk patients of choledocholithiasis based on the existing guidelines (ASGE guidelines 2010).

4. To find out the prognostic factors of choledocholithiasis at IOUS.

5. To evaluate the duration of hospitalisation, operation time and complications. 
* ASA score - American Society of Anesthesiologists Physical Status classification system

\subsection{Hypothesis of the Study}

IOUS significantly increases the diagnostic accuracy of choledocholithiasis compared to preoperative MRCP, allowing the replacement of MRCP with IOUS in a selective group of patients. In addition, it reduces the risk of complications, hospital stay, and ensures a safe recognition of anatomical structures during tissue dissection.

\subsection{Practical Value of the Study}

The study data show that IOUS is a safe, effective and rational imaging method of choledocholithiasis. IOUS allows significantly improving the diagnostic accuracy of choledocholithiasis, replacing preoperative MRCP in a large part of patients, and reducing the preoperative and overall hospitalisation time.

It is possible to repeat IOUS at any time during laparoscopic cholecystectomy when it is needed for diagnosis, bile duct content inspection after exploration and anatomical structure control, as well as exact visualisation of the structures at liver port during dissection. IOUS provides precise, realtime information of the bile duct content and detailed metrics of bile ducts to the surgeon, which form the cornerstone for choosing the safest and most effective method for bile duct sanation.

IOUS exam is very fast, so it does not prolong the operation time significantly. 


\section{MATERIALS AND METHODS}

Overall, 297 patients admitted between 2012 and 2017 were included in the study retrospectively. All patients were urgently admitted to Riga East University Hospital Clinic "Gailezers", Department of General and Emergency Surgery, specialised HPB (hepato-pancreato-biliary) surgery unit with symptomatic or/and complicated gallstone disease and suspected choledocholithiasis. During hospitalisation, laparoscopic cholecystectomy with IOUS was performed on all patients.

\subsection{Inclusion Criteria}

Patients over 18 years of age with gallstone disease and suspected choledocholithiasis were included in the study. Suspicions of choledocholithiasis were based on one of the following criteria:

- Acute biliary pancreatitis - diagnosis based on the Atlanta 2012 guidelines (Banks et al., 2013);

- Acute cholangitis - diagnosis suspected and proved according to the Tokyo 2018 guideline criteria (Kiriyama, Kozaka et al., 2018);

- Biliary (gallstone) colic, radiating back pain and/or an accompanying fever and small stones in the gall bladder $(<5 \mathrm{~mm})$.

\subsection{Exclusion Criteria}

- Patients with severe acute biliary pancreatitis (Atlanta criteria 2012) or severe acute cholangitis (Tokyo guidelines 2018);

- Patients converted to open surgery due to the uncontrolled bleeding, unclear anatomy or excessive inflammatory infiltrate. 


\subsection{Population of the Study Groups}

All patients were divided into two groups, depending on the IOUS finding during laparoscopy:

- IOUS verified choledocholithiasis (IOUS+);

- IOUS non-verified choledocholithiasis (IOUS-).

Standard laboratory analysis and TAUS were done at the time of admission on all patients. Complicated gallstone disease was diagnosed based on the above mentioned criteria.

Preoperative MRCP was done in a part of patients depending on the availability of the MRCP and diagnostic radiology, in both groups.

\subsection{Data Collection}

The data for a detailed assessment were retrieved from the medical charts and included the analysis of a patient's medical history, physiological status of comorbid conditions, laboratory and pre-operative imaging data. The success of laparoscopic surgery was analysed, including the findings of IOUS, bile duct exploration method and/or bile duct drainage techniques.

\subsection{Diagnostics and Treatment at the Time of Admission}

The examination of patients and the assessment of the patient's general condition were done by the surgical team on duty, under the supervision of chief surgeon. At this stage, the following procedures were completed:

- evaluation of disease anamnesis and clinical condition;

- evaluation of the patient's overall physical condition with an adapted ASA score (Sankar et al., 2014);

- laboratory diagnostics (full blood count; biochemistry - glucose, ALT, AST, total bilirubin and its fractions, lipase, alkaline phosphatase, C- 
reactive protein, creatinine, urea, potassium, sodium, Procalcitonin and blood gas analysis in patients with suspected sepsis; status of clotting - INR, prothrombin level, activated partial thromboplastin time);

- screening data of TAUS for the verification of gallstone disease and recognition of the direct or indirect signs of choledocholithiasis, as well as signs of acute pancreatitis and/or cholecystitis;

- ECG in patients over 50 years of age;

- computer tomography (with intravenous contrast agent if renal function was preserved) in patients with an unclear diagnosis;

- recognition of SIRS and MODS;

- intravenous rehydration and analgetics were administrated as needed, as well as early broad-spectrum antibacterial therapy in cases with cholangitis and/or cholecystitis (mostly Ciprofloxacin and Metronidazole).

During the time of admission, patients underwent intravenous rehydration and painkiller therapy as needed, as well as early broad-spectrum antimicrobial therapy for cholangitis and/or cholecystitis (mostly Ciprofloxacin and Metronidazole).

\subsection{Diagnostics and Treatment in the Department of Surgery}

The diagnostic plan and treatment for each patient was provided by a surgeon, under the unit chief surgeon's supervision. Patients received rehydration during the preoperative and perioperative period, painkillers and anti-inflammatory drugs. All patients were also treated with nitrate preparations (isosorbit mono- or dinitrate) before surgery if the individual tolerance of the preparation was satisfactory. The purpose was the relaxation of the muscle of 
the papilla Vateri for an eventual improvement in the bile drainage by means of conservative treatment and the facilitation of the spontaneous migration of gallstones into the duodenum if possible. Antimicrobial therapy was provided to patients with acute cholecystitis, cholangitis (TG18) and biliary pancreatitis (Atlanta 2012), as well as to patients with immunosuppression or diabetes. The choice of antimicrobial medication and the duration of treatment were based on clinical indications and recommendations developed by the infection monitoring service of the clinic (Liepiņš and Lejnieks, 2016).

According to the capacity of the department of radiology, some patients had pre-operative MRCP.

All patients were prepared for the one-stage surgical approach - LCBDE (intraoperative diagnostics provided by IOUS, followed by bile duct sanation if necessary, and cholecystectomy). In cases with biliary pancreatitis, surgery was performed after remission of the inflammation during the index admission.

\subsection{Surgery (Laparoscopy)}

Each operation had two main stages:

1. IOUS, followed by LCBDE in case of choledocholithiasis;

2. laparoscopic cholecystectomy.

\subsubsection{Intraoperative Ultrasonography}

Operations were performed with a classic four-trocar approach, after the formation of pneumoperitoneum trocars were positioned in the following way $10 \mathrm{~mm}$ through the umbilical ring for the camera and three for the manipulation - one of them $10 \mathrm{~mm}$ at epigastrium proprium and two $5 \mathrm{~mm}$ on the right side (Figure 2.1.). 


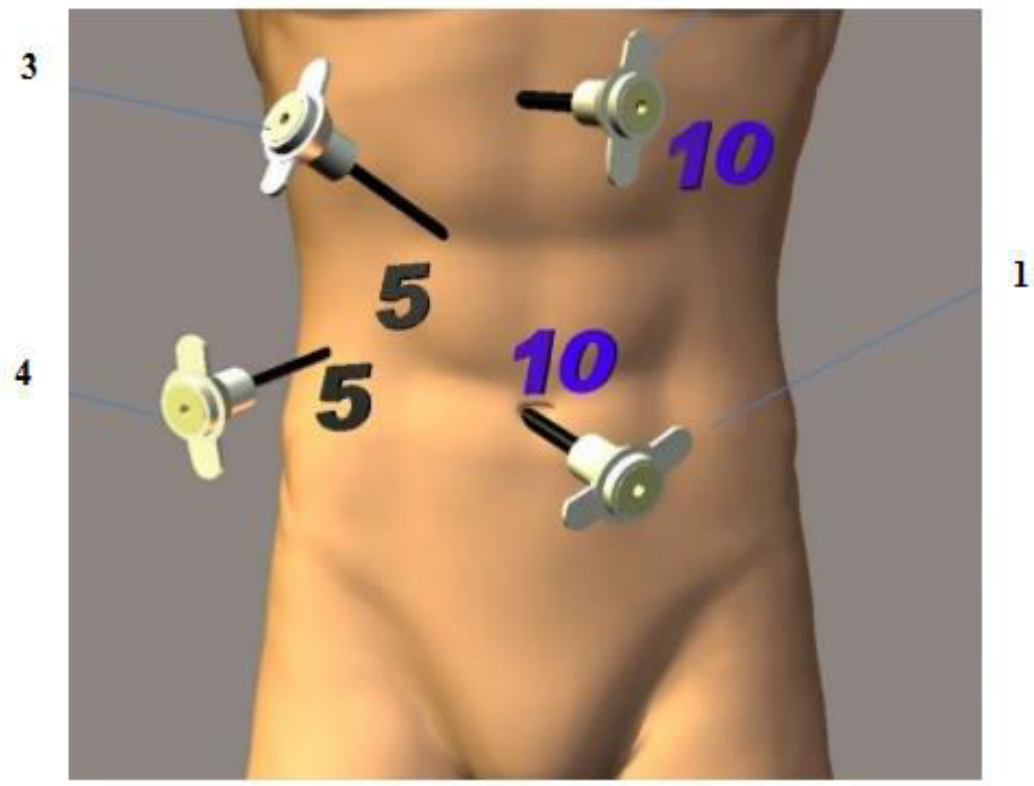

Figure 2.1. Positioning of trocars

(Image source: www.slideshare.net)

1 - umbilical trocar for camera $(10 \mathrm{~mm}) ; 2$ - epigastric trocar $(5 \mathrm{~mm} / 10 \mathrm{~mm}-15 \mathrm{~mm})$, main trocar for dissection, also for IOUS probe; 3 - trocar in the left hypochondria for the left hand $(5 \mathrm{~mm}) ; 4$ - trocar in the right lumbal region $(5 \mathrm{~mm})$ for traction of gallbladder

All adhesions from the gallbladder and hepatoduodenal ligament were dissected. Then the cystic duct was identified and clipped proximally close to the neck of the gallbladder.

All IOUS were done by a mobile ultrasound machine $B K$ Medical flex Focus 800 (Figure 2.2.) and a special, flexible probe for laparoscopic ultrasonography 8666- $R F$ (Figure 2.3.). 


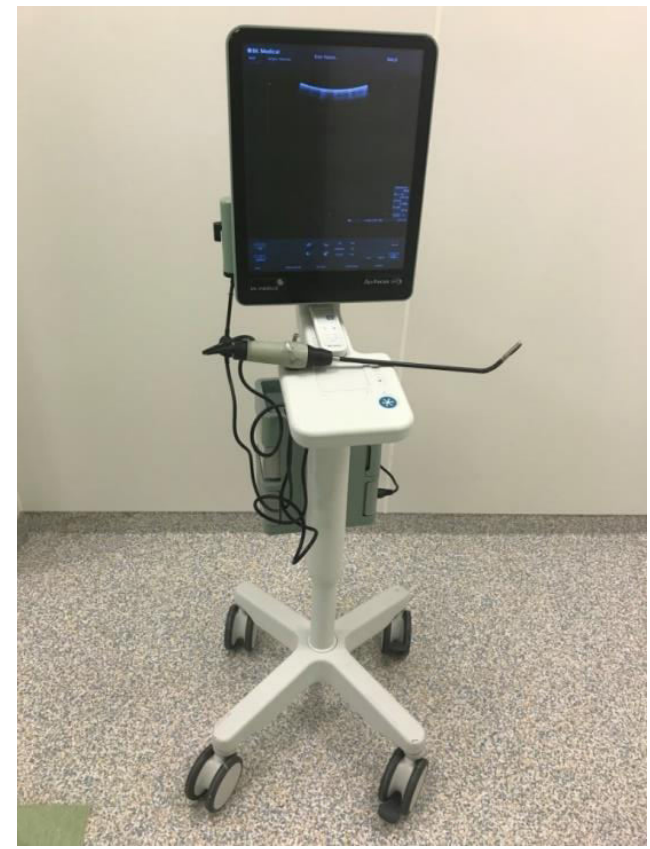

Figure 2.2. BK medical flex Focus 800 ultrasound machine (Photo by the author)

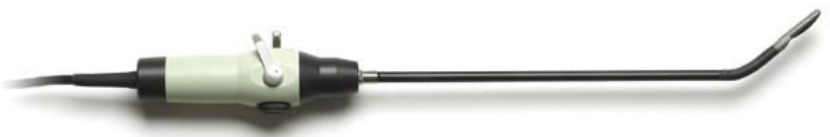

Figure 2.3. Probe for laparoscopic ultrasonography (Photo by the author)

An ultrasound probe was inserted into the abdominal cavity trough the epigastric trocar. After the fundus part of the gallbladder was lifted over the liver, scanning began with a gallbladder examination. The common hepatic duct and common bile duct were scanned when the IOUS probe was placed on 
the superior edge of the hepatoduodenal ligament (Figure 2.4.) and slid inferiorly to the distal end of the bile duct.

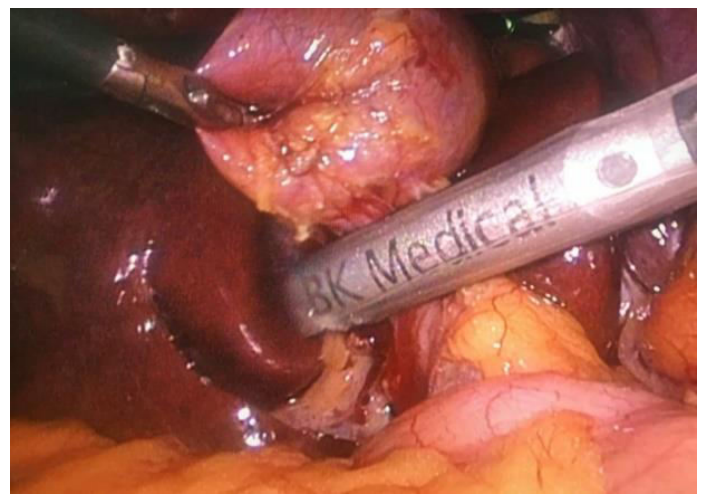

Figure 2.4. IOUS probe on the proximal part of hepatoduodenal ligament

(Photo by the author)

The distal part of the common bile duct (retroduodenal and intrapancreatic) and the area of the papilla Vateri were scanned through the duodenum (Figure 2.5.).

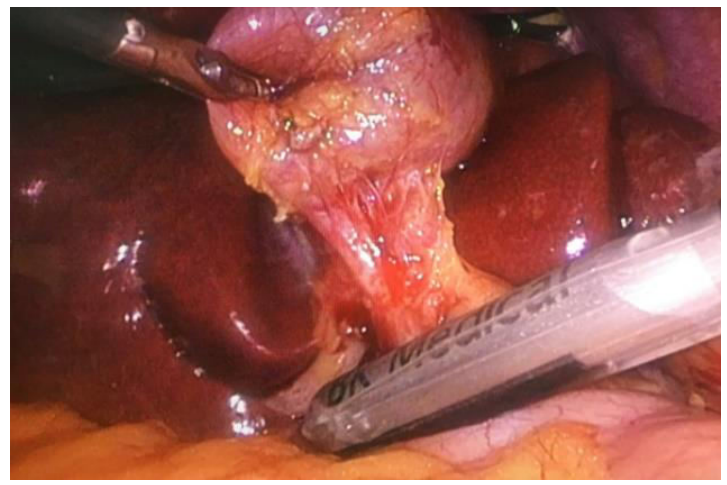

Figure 2.5. Scanning of the distal part of the common bile duct through the duodenum (Photo by the author) 
The left and right hepatic ducts and their junction were investigated through the right hepatic lobe. The Doppler function was used to differentiate structures from blood vessels (Figure 2.6.).

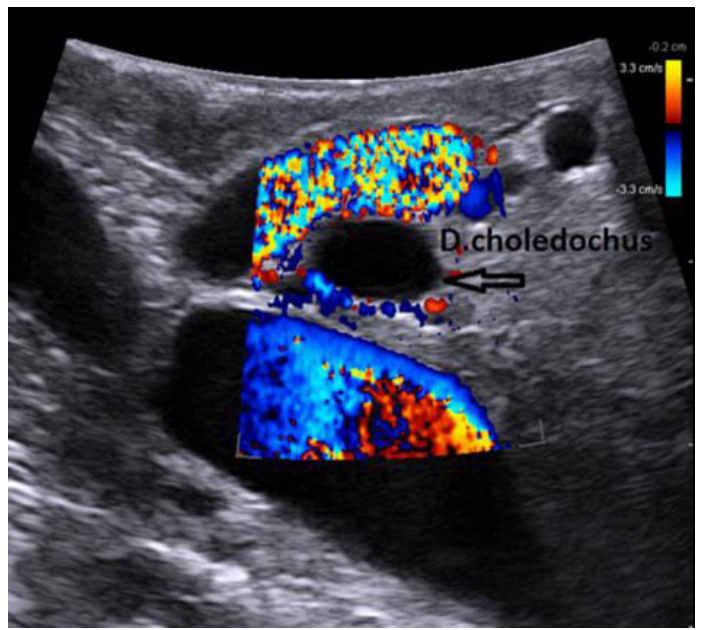

Figure 2.6. Common bile duct between blood vessels on Doppler (Photo by the author)

The main metrics examined in the study were the maximum width of the bile duct, its content (gallstones), the maximum size of the stone and the quantity of the concrements. Stones (Figure 2.7.) were considered as a positive finding at IOUS or choledocholithiasis, as well as biliary sludge (Figure 2.8.) in the lumen of the bile duct. 


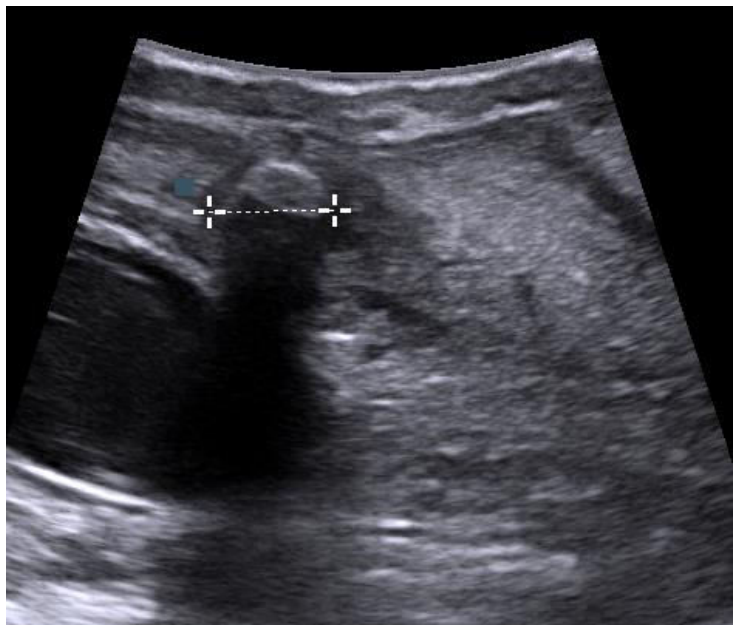

Figure 2.7. Stone in the bile duct obstructing the lumen

(Photo by the author)

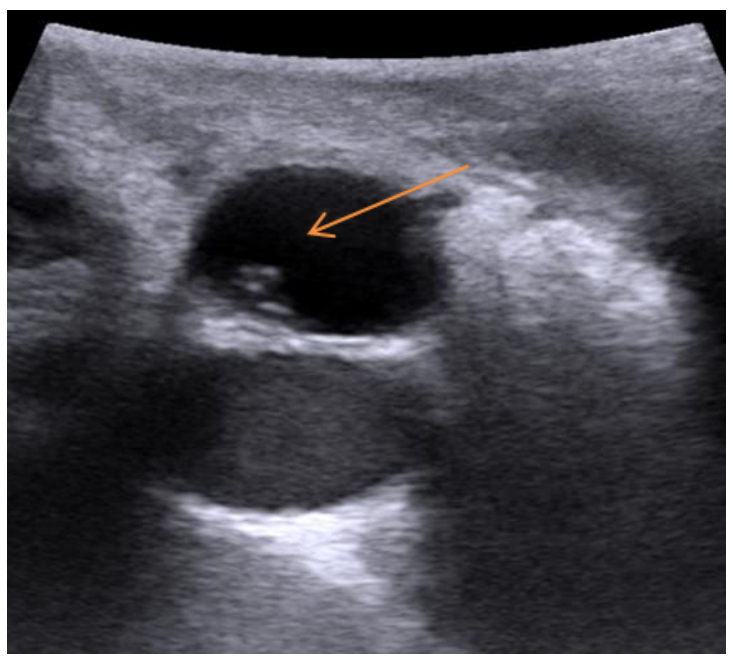

Figure 2.8. Sludge and small echogenic content $(<1 \mathrm{~mm})$ in the bile duct (Photo by the author) 


\subsubsection{Laparoscopic Common Bile Duct Exploration}

LCBDE was done following two main approaches - through the cystic duct and directly through the bile duct (ductotomy). The type of the bile duct sanation method was based on the IOUS finding (size of the bile duct and stones, the number of stones).

\section{Bile duct flushing}

In cases with sludge or small echogenic masses $(<1 \mathrm{~mm})$ in the lumen of the bile duct, sanation was performed with a special drain inserted in the bile duct through the cystic duct and flushed with a warm isotonic sodium chloride solution. Flushing was performed under IOUS control, to be sure that sludge is rinsed to the duodenum.

Transcystic choledochoscopy (Figure 2.9.)

Choledochoscopy was used when stones were larger than $2 \mathrm{~mm}$. Transcystic choledochoscopy was performed in cases when the size of the stones was up to $5 \mathrm{~mm}$, the number of the stones up to 8 and the width of the cystic duct at least $4 \mathrm{~mm}$.

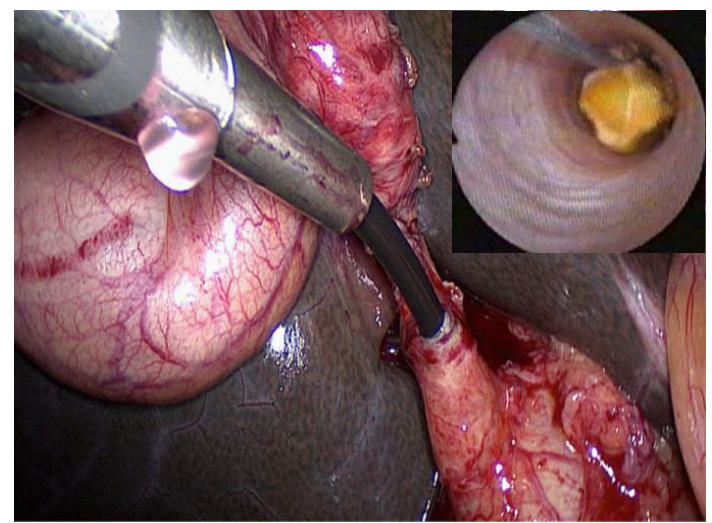

Figure 2.9. Laparoscopic transcystic choledochoscopy (Photo by the author) 


\section{Transductal bile duct exploration}

The transductal approach was used when size of the stones was greater than $6 \mathrm{~mm}$ and/or the number over 8 , as well as the size of the bile duct over one centimeter. In these cases, Fogarty type catheters (Figure 2.10.). were used for the bile duct clearance.

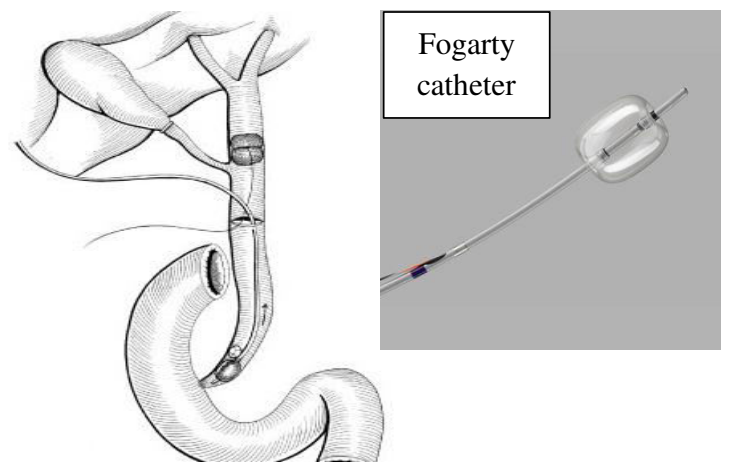

Figure 2.10. Transductal stone extraction from the bile duct with Fogarty type catheter

(Image source: http://www.scielo.br)

\section{Cholangiostomies}

In all cases during surgery, biliary drainage function (main purpose) was completely restored in cases of LCBDE failure or insufficient transpapillar biliary drainage, choledochostoma (controlled biliary fistula) was left. Transcystic choledochostoma - a type of stoma was inserted in the common bile duct through the cystic duct (Figure 2.11.). Transductal stoma or $\mathrm{T}$ tube or Kehr's drain - a drain inserted in the bile duct through a ductotomy (Figure 2.12.). 


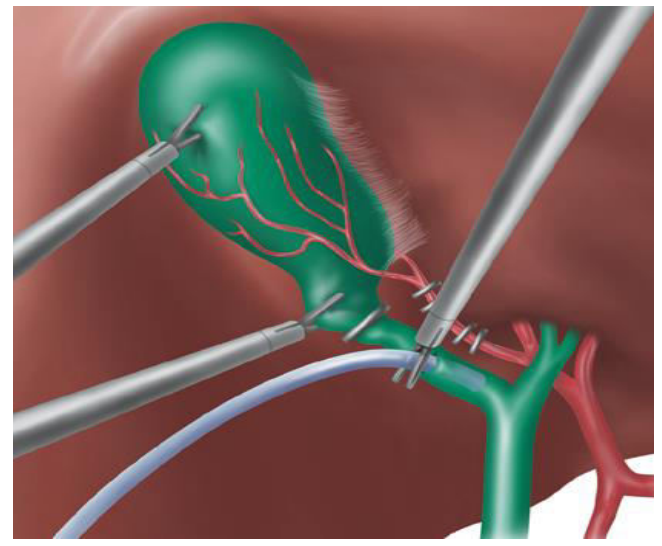

Figure 2.11. Insertion of the drain through the cystic duct into the common bile duct

(Image source: https://accesssurgery.mhmedical.com)

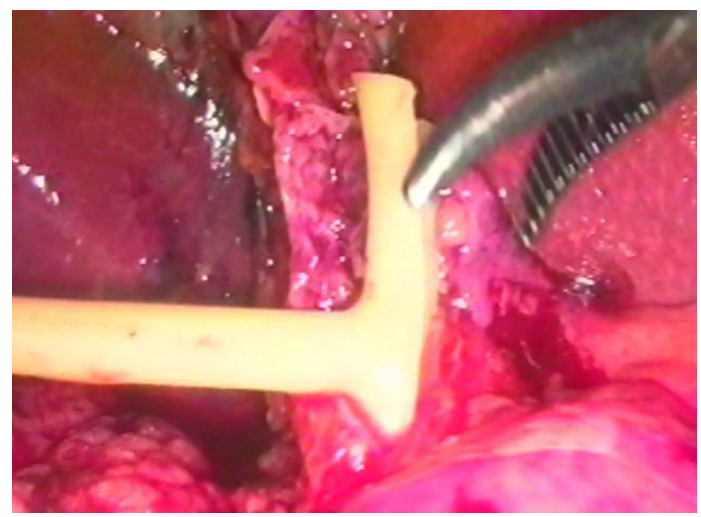

Figure 2.12. Insertion of the $\mathbf{T}$ tube into the bile duct through a ductotomy

(Image source: https://laparoscopy.blogs.com)

All patients with cholangiostomas had a fistulography (cholangiography) on the third day after surgery and only after the re-approval of choledocholithiasis or stenosis of the papilla, ERCP with endoscopic 
papillotomy was done. All choledochostomas were evacuated at the outpatient stage after the $10^{\text {th }}$ postoperative day.

In cases with an extensive bile duct dilatation and stenosis of the papilla, choledocho-duodenostomies were performed only in patients over 60 years of age.

\subsection{Statistical Analysis of the Data}

The interval data were expressed as a median (Me) with an interquartile range (IQR), because the breakdown of the data was asymmetric, confirmed by the Kolmogorov-Smirnov test. The Mann-Whitney U test was used to compare the interval data between the groups. Pearson $\chi 2$ and Fisher tests were used to compare the nominal data between the groups. The correlation between the preoperative and total hospital stay and clinical data was calculated by the Spearman rho method. A logical regression analysis was performed to identify factors associated with a longer hospital stay. The results were considered statistically significant at the p-value of $<0.05$ and confidence interval of $95 \%$. Statistical analysis was performed with the SPSS software (version 20) and MedCalc (version 15).

\subsection{Decision of the Ethics Committee}

Permission for the study was received from the Ethics Committee of Rīga Stradiņš University No 6-3/56, and the study was conducted in accordance with ethical principles of the Helsinki Declaration (World Medical Association, 2013). 


\section{RESULTS}

\subsection{Structure and Demographics of Patients}

According to the criteria, 297 patients were included in the study. Women were statistically prevalent than men $(n=210 / n=87 ; p=0.001)$; however, the median age of men was significantly higher than of women - Me 65 (IQR 74-55) vs. Me 58 (IQR 68-45), p = 0.035.

According to the criteria of the ASA score, it was found that most patients had moderate and severe comorbidities without decompensation. Statistically significantly more women had the ASA I score without any differences in other ASA scores.

\subsection{Distribution of Patient Groups}

Overall, 178 cases of choledocholithiasis were found during surgery on IOUS - $59.93 \%$ (IOUS+ group), while in 119 patients or $40.07 \%$ choledocholithiasis was not verified (IOUS- group).

\subsection{Comparison of Groups}

Choledocholithiasis was significantly less common in patients without comorbidities (ASA I), and there was no difference in the incidence of choledocholithiasis between other ASA groups. However, in patients with a worse overall physical condition (a higher ASA score), choledocholithiasis was more common during surgery - there was a weak correlation between the ASA score and choledocholithiasis on IOUS $(r=0.12 ; p=0.039)$. Binary regression analysis showed that patients with a higher ASA score were 1.42 times more likely to have a positive IOUS finding. Positive IOUS findings were more 
common in older men. Preoperative MRCP was done in the IOUS+ group patients significantly more often.

The most significant laboratory and clinical data are shown in Table 3.1.

Table 3.1

Biochemical and clinical parameters in groups

\begin{tabular}{|c|c|c|c|c|}
\hline \multirow[t]{2}{*}{$\begin{array}{l}\text { Biochemical } \\
\text { parameters }\end{array}$} & \multirow[t]{2}{*}{$\begin{array}{c}\text { Cohort } \\
\text { Me (IQR) }\end{array}$} & $\begin{array}{c}\text { IOUS+ group } \\
\quad(n=178)\end{array}$ & $\begin{array}{c}\text { IOUS- group } \\
(\mathrm{n}=119)\end{array}$ & \multirow[t]{2}{*}{$\begin{array}{c}\mathbf{p} \\
\text { value }\end{array}$} \\
\hline & & Me (IQR) & Me (IQR) & \\
\hline CRP, mg/L & $7(24-2)$ & $8.3(38-4)$ & $6(15-2)$ & 0.022 \\
\hline ALT, U/L & $230(464-94)$ & $243(473-108)$ & $216(447-75)$ & 0.155 \\
\hline AST, U/L & $188(371-63)$ & $189(405-58)$ & $188(333-71)$ & 0.972 \\
\hline $\mathrm{AF}, \mathrm{U} / \mathrm{L}$ & $\begin{array}{c}195(278- \\
130)\end{array}$ & $216(316-131)$ & $172(249-122)$ & 0.061 \\
\hline $\begin{array}{l}\text { Bilirubin total, } \\
\mu \mathrm{mol} / \mathrm{L}\end{array}$ & $34(66-15)$ & $39(84-20)$ & $29(52-13)$ & 0.001 \\
\hline $\begin{array}{l}\text { Bilirubin direct, } \\
\mu \mathrm{mol} / \mathrm{L}\end{array}$ & $24(53-8)$ & $28(67-10)$ & $18(37-7)$ & 0.001 \\
\hline Lipase, U/L & $64(2268-34)$ & $56.9(857-32)$ & $147(4323-37)$ & 0.004 \\
\hline $\begin{array}{l}\text { Clinical } \\
\text { conditions }\end{array}$ & Cohort, n & n $(\%)$ & n $(\%)$ & $\underset{\text { value }}{\mathbf{p}}$ \\
\hline $\begin{array}{l}\text { Mechanical } \\
\text { jaundice* }\end{array}$ & 147 & $100(56.5)$ & $47(39.5)$ & 0.009 \\
\hline Cholangitis & 134 & $107(60.1)$ & $27(22.7)$ & $\begin{array}{c}< \\
0.001\end{array}$ \\
\hline Cholecystitis & 194 & $118(66.3)$ & $76(63.9)$ & 0.813 \\
\hline $\begin{array}{l}\text { Biliary } \\
\text { pancreatitis }\end{array}$ & 110 & 55 (30.9) & $55(46.2)$ & 0.005 \\
\hline
\end{tabular}

*total bilirubin > $34.2 \mathrm{~g} / \mathrm{dL}$ (Tokyo guidelines 2018)

A statistically significant higher inflammatory response, higher bilirubin level, more commonly defined mechanical jaundice (> $34.2 \mathrm{~g} / \mathrm{dL}$; Tokyo guidelines 2018) and cholangitis were observed in patients with a positive IOUS finding. However, the level of liver enzymes and alkaline phosphatase were similar in both groups. Moreover, significantly higher lipase levels were found in the patient group with a negative IOUS finding (IOUS-) - a median of 147 (IQR 4323-37), $\mathrm{p}=0.004$. Similarly, biliary pancreatitis was statistically 
significantly more commonly diagnosed in the IOUS- group patients $(p=0.005)$. Acute cholecystitis was equally common in both groups.

\subsection{Characteristics of Trans-Abdominal Ultrasonography}

Of all 297 patients, preoperative TAUS was done in 278 (93.6\%). TAUS was performed in 167 patients $(93.8 \%)$ of the IOUS+ group, and in 111 $(93.3 \%)$ of the IOUS- group patients. The median value (Me) of the bile duct width in the patient cohort that underwent TAUS was 7 (IQR 10-5) millimeters.

\subsubsection{Analysis of the Bile Duct Size on Trans-Abdominal Ultrasonography in Groups}

A statistically significantly higher median value of the bile duct width during preoperative TAUS was observed in patients with a positive IOUS finding (IOUS+ group), compared to the IOUS- patients, $\mathrm{p}<0.001$ (Figure 3.1.).

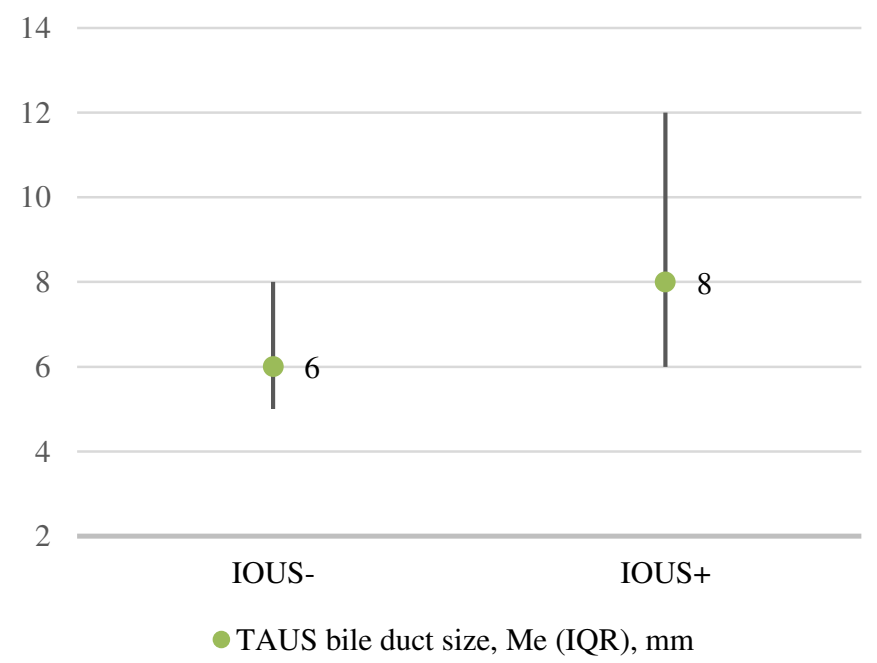

Figure 3.1. Median values of the bile duct size on TAUS in groups 
As shown in Table 3.2., with a statistical significance, in patients with a dilated bile duct on TAUS (> $6 \mathrm{~mm}$ ), choledocholithiasis was more frequently verified on IOUS, $\mathrm{p}<0.001$.

Table 3.2

Bile duct dilatation on TAUS $(>/ \leq 6 \mathrm{~mm})$ in groups

\begin{tabular}{|l|c|c|c|}
\hline $\begin{array}{l}\text { Width of the bile } \\
\text { duct on TAUS, } \mathbf{m m}\end{array}$ & $\begin{array}{c}\text { IOUS+ } \\
\mathbf{n}(\boldsymbol{\%})\end{array}$ & $\begin{array}{c}\text { IOUS- } \\
\mathbf{n}(\boldsymbol{\%})\end{array}$ & $\begin{array}{c}\text { Total, } \mathbf{n} \\
(\boldsymbol{\%})\end{array}$ \\
\hline$>6$ & $115(71.9)$ & $45(28.1)$ & $160(100)$ \\
\hline$\leq 6$ & $52(44.1)$ & $66(55.9)$ & $118(100)$ \\
\hline
\end{tabular}

Binary regression analysis showed a statistically significant relationship between the IOUS finding and the predisposing factors: the size (width) of the bile duct on TAUS (as an interval indicator), a dilatation of the bile duct over 6 $\mathrm{mm}$ and a dilatation of the intrahepatic bile ducts (Table 3.3.).

Table 3.3

TAUS-identifiable risk factors of choledocholithiasis on IOUS

\begin{tabular}{|l|c|c|c|}
\hline $\begin{array}{l}\text { Risk factors of IOUS-detected } \\
\text { choledocholithiasis }\end{array}$ & $\begin{array}{c}\text { Odds } \\
\text { ratio }\end{array}$ & $\begin{array}{c}\text { 95 \% confidence } \\
\text { interval, \% }\end{array}$ & p value \\
\hline Bile duct size on TAUS & 1.22 & $1.12-1.33$ & $<0.001$ \\
\hline Bile duct $>$ 6 mm on TAUS & 3.15 & $1.9-5.2$ & 0.002 \\
\hline $\begin{array}{l}\text { Dilatation of the intrahepatic } \\
\text { bile ducts on TAUS }\end{array}$ & 3.74 & $1.79-7.78$ & $<0.001$ \\
\hline
\end{tabular}

\subsubsection{Diagnosis of Choledocholithiasis on Trans-Abdominal Ultrasonography in Groups}

From all TAUS examinations, in 38 cases $(13.7 \%)$ choledocholithiasis was verified, and later proved by IOUS in 32 patients - the IOUS+ group (a true positive TAUS finding) but disproved in 6 patients - the IOUS- group (a false positive TAUS finding), $\mathrm{p}=0.001$. 
There was a weak, but statistically significant correlation between the verified choledocholithiasis on TAUS and a positive IOUS finding $(r=0.197$; $\mathrm{p}=0.001)$. Binary regression analysis showed that between the dependent indicator - the IOUS finding and the prognostic factor - TAUS-verified choledocholithiasis had a statistically significant odds ratio of 4.2 (95\% confidence interval 1.69-10.4), $\mathrm{p}=0.002$. This indicates that patients with verified choledocholithiasis on TAUS have a 4.2 times higher likelihood that choledocholithiasis on IOUS will also be recognised.

\subsection{Characteristics of Magnetic Resonance Cholangio- Pancreatography Finding}

Preoperative MRCP was performed in 87 patients from the cohort $(29.3 \%)$. In the IOUS+ group, MRCP was done in 60 patients $(33.7 \%)$ and in the IOUS- group in 27 patients $(22.7 \%)$. There was no statistically significant difference (demographic data, ASA score, and clinical data) between the patients with and without preoperative MRCP.

\subsubsection{Analysis of the Bile Duct Size on Magnetic Resonance Cholangio-Pancreatography in Groups}

The median value (Me) of the bile duct on MRCP in the whole cohort was 6 (IQR 9-4) millimeters, and in the IOUS+ group it was significantly higher than in the IOUS- group, $\mathrm{p}<0.001$ (Figure 3.2.). A moderate positive correlation between these values was observed $(r=0.432 ; p<0.001)$. 


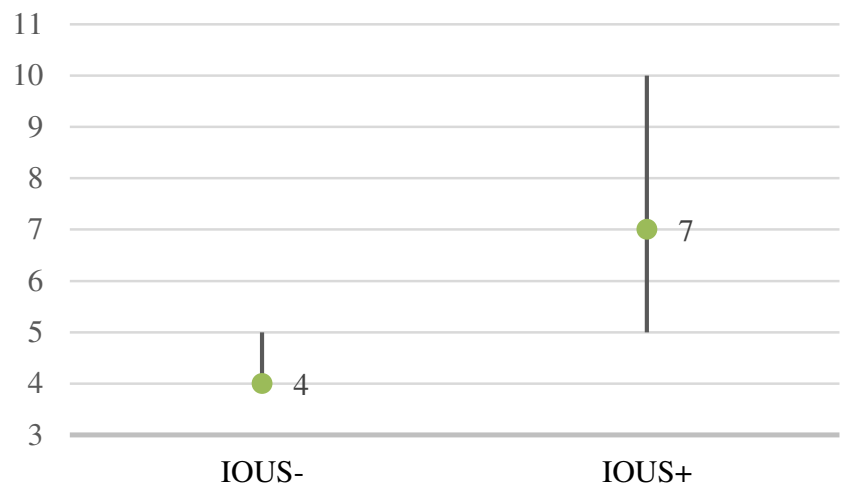

- MRCP bile duct size, Me (IQR), mm

Figure 3.2. Median values of bile duct sizes on MRCP in groups

A statistically significant positive correlation was observed between the bile duct size on MRCP and a positive finding on IOUS during surgery $(\mathrm{r}=$ $0.419 ; \mathrm{p}<0.001)$ (Table 3.4.).

Table 3.4

Bile duct dilatation on $\mathrm{MRCP}(>\mid \leq 6 \mathrm{~mm})$ in groups

\begin{tabular}{|l|c|c|c|}
\hline $\begin{array}{l}\text { Width of the bile } \\
\text { duct on MRCP, mm }\end{array}$ & $\begin{array}{c}\text { IOUS+ } \\
\mathbf{n}(\boldsymbol{\%})\end{array}$ & $\begin{array}{c}\text { IOUS- } \\
\mathbf{n}(\boldsymbol{\%})\end{array}$ & $\begin{array}{c}\text { Total } \\
\mathbf{n}(\boldsymbol{\%})\end{array}$ \\
\hline$>6$ & $34(89.5)$ & $4(10.5)$ & $38(100)$ \\
\hline$\leq 6$ & $26(53)$ & $23(47)$ & $49(100)$ \\
\hline
\end{tabular}

Binary regression analysis showed a statistically significant relationship between the dependent factors - the IOUS finding and predisposing factors: bile duct size or width (as an interval indicator), bile duct dilation over $6 \mathrm{~mm}$ and defined choledocholithiasis on MRCP. A statistically significant, but relatively low odds ratio was found in the bile duct size on MRCP for verifying choledocholithiasis on IOUS; however, in comparison with a similar TAUS 
analysis, it was higher. A remarkably higher odds ratio for the verification of choledocholithiasis on IOUS was in the bile duct dilatation over $6 \mathrm{~mm}$ on MRCP and in verified choledocholithiasis on MRCP (Table 3.5.).

Table 3.5

MRCP-identifiable risk factors of choledocholithiasis on IOUS

\begin{tabular}{|l|c|c|c|}
\hline $\begin{array}{l}\text { Risk factors of the IOUS } \\
\text { detected choledocholithiasis }\end{array}$ & $\begin{array}{c}\text { Odds } \\
\text { ratio }\end{array}$ & $\begin{array}{c}\text { 95 \% confidence } \\
\text { interval, \% }\end{array}$ & p value \\
\hline Bile duct size on MRCP & 1.62 & $1.22-2.17$ & 0.001 \\
\hline Bile duct > 6 mm on MRCP & 10.03 & $2.7-37.1$ & 0.001 \\
\hline $\begin{array}{l}\text { MRCP proved } \\
\text { choledocholithiasis }\end{array}$ & 19.3 & $4.2-89.5$ & $<0.001$ \\
\hline
\end{tabular}

There were 22 cases with a dilatation of the intrahepatic bile ducts on MRCP. In all of these patients, choledocholithiasis was approved on IOUS $(\mathrm{p}<0.001)$. This value had a statistically significant positive correlation with choledocholithiasis on IOUS $(r=0.386 ; \mathrm{p}<0.001)$. However, the absence of the intrahepatic bile duct dilatation on MRCP is not reliable for the prognosis of the IOUS finding (binary regression analysis showed that this parameter was not statistically significant $-\mathrm{p}=0.998$ ).

\subsubsection{Magnetic Resonance Cholangio-Pancreatography Finding Controlled by Intraoperative Ultrasonography}

In 39 patients (44.8 \% from all MRCPs) choledocholithiasis was identified at the preoperative stage by MRCP. In 37 of them, it was also confirmed during surgery on IOUS (a true positive MRCP finding) and in 2 of them it was not confirmed (a false positive MRCP finding). However, out of the other 47 patients with no choledocholithiasis on MRCP, in 23 cases it was detected afterwards during surgery on IOUS (a false negative MRCP finding $38.3 \%), \mathrm{p}<0.001$. A true negative MRCP finding was observed in 24 patients (Figure 3.3.). 


\begin{tabular}{|c|c|c|c|}
\hline $\mathrm{n}(\%)$ & MI & + & Total \\
\hline $\begin{array}{l}\mathscr{\infty} \\
\stackrel{2}{0}+\end{array}$ & $\begin{array}{l}24(92.1) \\
23(38.3)\end{array}$ & $\begin{array}{c}2(7.7) \\
37(61.7)\end{array}$ & $\begin{array}{l}26(100) \\
60(100)\end{array}$ \\
\hline Total & $47(54.7)$ & $39(45.3)$ & $86 *(100)$ \\
\hline
\end{tabular}

Figure 3.3. Diagnostic value of MRCP in diagnosis of choledocholithiasis, controlled by IOUS

\subsubsection{Diagnostic Value of Magnetic Resonance Cholangio- Pancreatography in the Detection of Choledocholithiasis}

Based on the above mentioned data, the diagnostic value of MRCP was obtained in the study population (Table 3.6).

Table 3.6

Diagnostic value of MRCP

\begin{tabular}{|l|c|c|}
\hline $\begin{array}{l}\text { Criteria of diagnostic } \\
\text { value }\end{array}$ & $\%$ & $\begin{array}{c}\mathbf{9 5} \% \text { confidence } \\
\text { interval, \% }\end{array}$ \\
\hline Sensitivity & 61.7 & $54.6-64.4$ \\
\hline Specificity & 92.3 & $76.1-98.6$ \\
\hline Positive predictive value & 94.9 & $84.1-99.1$ \\
\hline Negative predictive value & 51.1 & $42.1-54.6$ \\
\hline
\end{tabular}

A significantly higher diagnostic value of MRCP was observed when patients with sludge and small stones $\leq 1 \mathrm{~mm}$ in the bile duct on IOUS were excluded from the data analysis (Table 3.7.). 


\section{Diagnostic value of MRCP*}

\begin{tabular}{|l|c|c|}
\hline $\begin{array}{l}\text { Criteria of diagnostic } \\
\text { value }\end{array}$ & \% & $\begin{array}{c}\text { 95 \% confidence } \\
\text { interval, \% }\end{array}$ \\
\hline Sensitivity & 82.9 & $73.6-86.9$ \\
\hline Specificity & 92 & $76.7-98.5$ \\
\hline Positive predictive value & 94.4 & $83.8-99$ \\
\hline Negative predictive value & 76.7 & $64-82.1$ \\
\hline
\end{tabular}

* Analysis was performed without patients with sludge and stones $\leq 1 \mathrm{~mm}$ on IOUS.

MRCP data analysis in different clinical groups has shown that choledocholithiasis was found significantly more often in patients with acute cholangitis (Table 3.8.).

Table 3.8

MRCP finding in different clinical groups

\begin{tabular}{|l|c|c|c|}
\hline Clinical group & $\begin{array}{c}\text { MRCP } \\
\text { no choledocholithiasis } \\
\mathbf{n}(\boldsymbol{\%})\end{array}$ & $\begin{array}{c}\text { MRCP } \\
\text { choledocholithiasis } \\
\mathbf{n}(\boldsymbol{\%})\end{array}$ & p value \\
\hline Cholangitis & $18(38.3)$ & $24(60)$ & 0.043 \\
\hline Cholecystitis & $33(70.2)$ & $25(62.5)$ & 0.447 \\
\hline Biliary pancreatitis & $25(53.2)$ & $15(37.5)$ & 0.143 \\
\hline Mechanical jaundice & $27(57.4)$ & $26(65)$ & 0.472 \\
\hline
\end{tabular}

Proven choledocholithiasis on MRCP had a statistically significant correlation with choledocholithiasis during surgery on IOUS $(r=0.498$; $\mathrm{p}<$ 0.001). The important fact is that the size of stones not diagnosed on MRCP (23 patients) was a median of 3 (IQR 3-1) millimeters at the time of surgery diagnosed by IOUS; however, the size of the stones diagnosed by both methods (MRCP and IOUS) was statistically significantly higher - a median of 5 (IQR 7-4) millimeters, $\mathrm{p}<0.001$. 


\subsection{Characteristics of the Intraoperative Ultrasonography Finding}

IOUS was performed in all 297 patients of the study regardless of preoperative imaging and its results.

\subsubsection{Analysis of the Bile Duct Size on Intraoperative Ultrasonography in Groups}

The median size of the bile duct on IOUS in the whole cohort was 8 (IQR 11-6) millimeters and it was significantly higher in the IOUS+ group patients compared to IOUS- (Figure 3.4.), p < 0.001. A moderate positive correlation was observed between the bile duct width on IOUS and a positive finding $(\mathrm{r}=0.511 ; \mathrm{p}<0.001)$.

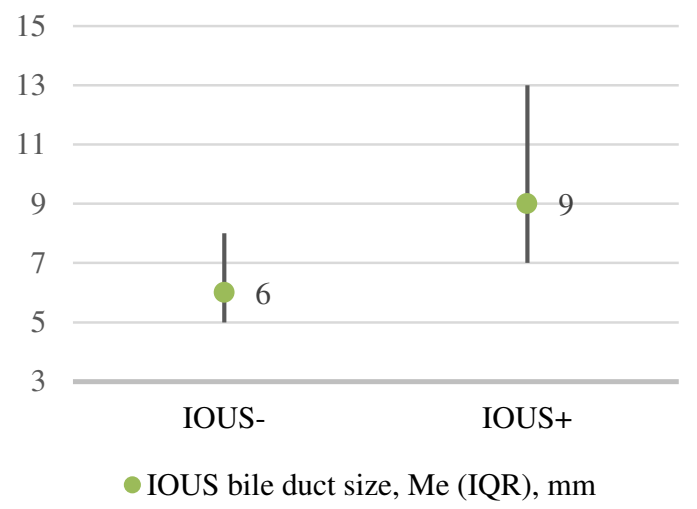

Figure 3.4. Median values of bile duct sizes on IOUS in groups

Bile duct dilatation (> $6 \mathrm{~mm}$ ) in the study population was more commonly found on IOUS compared to MRCP (Figure 3.5.). 


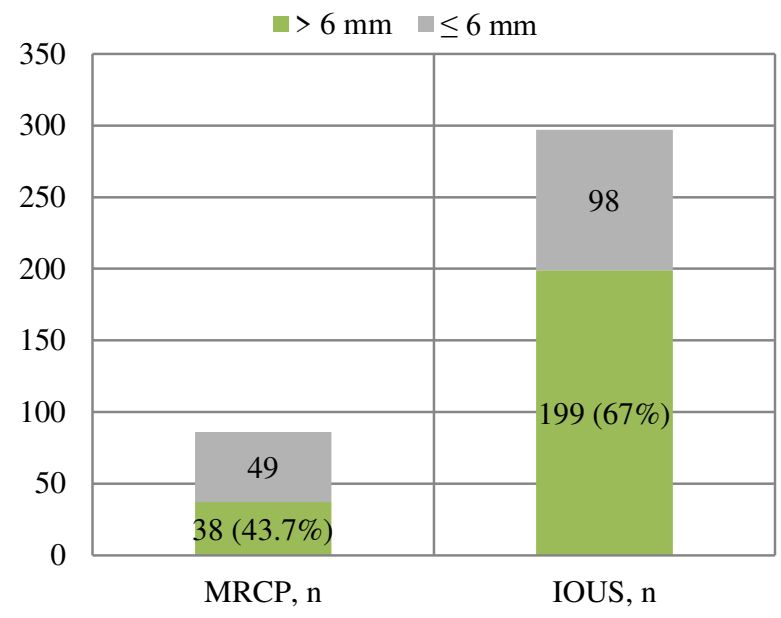

Figure 3.5. Bile duct dilatation of cohort patients on MRCP and IOUS

Moreover, binary regression analysis showed a statistically significant ( $\mathrm{p}$ $=0.001)$ odds ratio of IOUS bile duct dilatation in the detection of choledocholithiasis on IOUS - 8.97 (95\% confidence interval 5.0-15.9).

\subsubsection{Diagnosis of Choledocholithiasis in Groups}

During surgery, choledocholithiasis was diagnosed on IOUS in 178 patients $(59.93 \%)$ from the cohort. In $15.8 \%$, the bile duct was not dilatated $(\leq 6 \mathrm{~mm})$ and in $84.2 \%$ the bile duct was wider than $6 \mathrm{~mm}$. Evidence from the previous studies demonstrated that choledocholithiasis was also frequently observed in a non-dilated $(\leq 6 \mathrm{~mm})$ bile duct recognised on IOUS. Contrary to that, in about one quarter of patients with a dilated bile duct ( $>6 \mathrm{~mm})$ on IOUS choledocholithiasis was not found (Figure 3.6.). 
297 patients

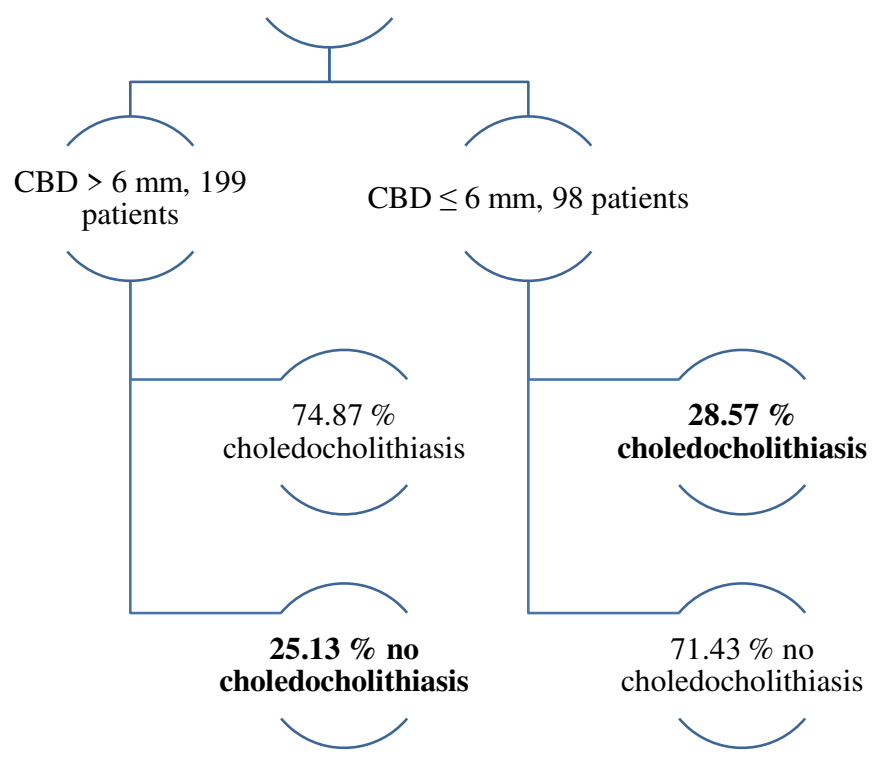

Figure 3.6. IOUS finding depending on bile duct dilatation $(>\mid \leq 6 \mathrm{~mm})$

During the two-year period, from the cohort of 297 patients a follow-up revealed the necessity to readmit 9 patients $(3.13 \%)$ due to residual stones, diagnosed previously on IOUS in 8 (IOUS+ group), while for one patient choledocholithiasis was not diagnosed on IOUS during the first intervention (IOUS- group). Based on the data, the diagnostic value of intraoperative ultrasonography was determined (Table 3.9.). All re-hospitalised patients had successfully undergone endoscopic biliary treatment (ERCP). 
Diagnostic value of IOUS

\begin{tabular}{|l|c|c|}
\hline $\begin{array}{l}\text { Criteria of diagnostic } \\
\text { value }\end{array}$ & $\%$ & $\begin{array}{c}\text { 95 \% confidence } \\
\text { interval, \% }\end{array}$ \\
\hline Sensitivity & 99.4 & $97.1-100$ \\
\hline Specificity & 94.3 & $91-95.1$ \\
\hline Positive predictive value & 96.1 & $93.8-96.6$ \\
\hline Negative predictive value & 99.1 & $95.7-100$ \\
\hline
\end{tabular}

\subsection{Analysis of the Median Size of Stones on Magnetic Resonance Cholangio-Pancreatography and Intraoperative Ultrasonography}

There were no statistically significant differences in the mean sizes of gallstones in the bile duct verified on MRCP or IOUS, $\mathrm{p}=0.361$ (Table 3.10.); however, it was at opposite sides of the $5 \mathrm{~mm}$ borderline which is an important value in the choice of the exploration approach.

Table 3.10

Median size of stones on MRCP and IOUS in patients with choledocholithiasis

\begin{tabular}{|l|c|c|}
\hline Diagnostic method & Me & IQR \\
\hline MRCP, mm & 6 & $9-4$ \\
\hline IOUS, mm & 4 & $7-3$ \\
\hline
\end{tabular}

\subsection{Diagnostic Value of Intraoperative Ultrasonography and Magnetic Resonance Cholangio-Pancreatography in Low, Intermediate and High Risk Patients of Choledocholithiasis}

According to the assessment criteria published in the ASGE guidelines (patient's age, biochemical markers of liver function and TAUS), patients were divided into three groups of risk of choledocholithiasis: low $(<10 \%)$, medium $(10-50 \%)$ and high $(>50 \%)$. 
Data analysis revealed that no low-risk patients were examined with MRCP. In medium and high-risk groups, the expected incidence of choledocholithiasis was in accordance with the guidelines $-26 \%$ and $53.1 \%$, respectively (Table 3.11.).

Table 3.11

Diagnostic value of MRCP in risk groups of choledocholithiasis

\begin{tabular}{|l|c|c|c|}
\hline MRCP finding & $\begin{array}{c}\text { Medium risk } \\
\mathbf{n}(\mathbf{\%})\end{array}$ & $\begin{array}{c}\text { High risk } \\
\mathbf{n}(\mathbf{\%})\end{array}$ & $\begin{array}{c}\text { Total } \\
\mathbf{n}(\mathbf{\%})\end{array}$ \\
\hline No choledocholithiasis & $17(74)$ & $30(46.9)$ & $47(54)$ \\
\hline Choledocholithiasis & $6(\mathbf{2 6})$ & $34(\mathbf{5 3 . 1})$ & $40(46)$ \\
\hline Total & $23(100)$ & $64(100)$ & $87(100)$ \\
\hline
\end{tabular}

The absolute majority of patients investigated with IOUS were in the medium and high risk groups of choledocholithiasis. In these groups, choledocholithiasis was detected in $35.8 \%$ and $75.5 \%$, which was in accordance with the recommendations in the guidelines (Table 3.12.), and the incidence of choledocholithiasis in these groups was significantly higher on IOUS compared to MRCP, $\mathrm{p}<0.001$.

Table 3.12

Diagnostic value of IOUS in risk groups of choledocholithiasis

\begin{tabular}{|l|c|c|c|c|}
\hline IOUS finding & $\begin{array}{c}\text { Low risk } \\
\mathbf{n}(\boldsymbol{\%})\end{array}$ & $\begin{array}{c}\text { Medium risk } \\
\mathbf{n}(\boldsymbol{\%})\end{array}$ & $\begin{array}{c}\text { High risk } \\
\mathbf{n}(\boldsymbol{\%})\end{array}$ & $\begin{array}{c}\text { Total } \\
\mathbf{n}(\boldsymbol{\%})\end{array}$ \\
\hline No choledocholithiasis & $4(80)$ & $68(64.2)$ & $45(24.5)$ & $117(39.7)$ \\
\hline Choledocholithiasis & $1(20)$ & $38(35.8)$ & $139(\mathbf{7 5 . 5})$ & $178(60.3)$ \\
\hline Total & $5(100)$ & $106(100)$ & $184(100)$ & $295(100)^{*}$ \\
\hline
\end{tabular}

*Data required for groups performing available in 295 from 297 patients

\subsection{Analysis of the Duration of Surgery in Groups}

The median time of surgery in the cohort patients was 70 (IQR 100-50) minutes. However, in the IOUS+ group patients, the duration of operation was 
significantly longer than in the IOUS- group patients - a median of 85 (IQR 115-65) minutes vs. 55 (IQR 75-45) minutes, $\mathrm{p}<0.001$. A statistically significant medium positive correlation was observed between these groups in cases of verified choledocholithiasis during surgery on IOUS, the time of operation was longer $(r=0.451 ; p<0.001)$. The median duration of the IOUS examination was 2 (IQR 4-2) minutes, which did not significantly prolong the total time of operation.

\subsection{Analysis of the Duration of Hospitalisation}

The total hospital stay and postoperative period were significantly longer in the IOUS+ group patients compared to the IOUS- group (Table 3.13.).

Table 3.13

Duration of hospitalisation in groups

\begin{tabular}{|l|c|c|c|}
\hline Me (IQR), days & $\begin{array}{c}\text { IOUS+ } \\
\text { n 178 }\end{array}$ & $\begin{array}{c}\text { IOUS- } \\
\text { n 119 }\end{array}$ & p value \\
\hline Total hospital stay & $10(13-7)$ & $8(10-6)$ & $<0.001$ \\
\hline Preoperative period & $5(7-3)$ & $5(7-3)$ & 0.655 \\
\hline Postoperative period & $5(8-3)$ & $3(4-2)$ & $<0.001$ \\
\hline
\end{tabular}

The following finding is notable as well - the preoperative and total hospital stay were significantly longer in patients in whom preoperative MRCP was done. The postoperative hospital stay did not differ when preoperative MRCP was applied (Table 3.14.).

Table 3.14

Duration of hospitalisation depending from MRCP

\begin{tabular}{|l|c|c|c|}
\hline Me (IQR), days & $\begin{array}{c}\text { MRCP } \\
\text { n 87 }\end{array}$ & $\begin{array}{c}\text { No MRCP } \\
\text { n 210 }\end{array}$ & p value \\
\hline Total hospital stay & $11(14-9)$ & $8(11-6)$ & 0.001 \\
\hline Preoperative period & $6(8-5)$ & $4(6-2)$ & $<0.001$ \\
\hline Postoperative period & $4(7-2)$ & $4(5-2)$ & 0.185 \\
\hline
\end{tabular}




\subsection{Assessment of Complications}

The application of IOUS was not associated with complications due to the non-invasiveness and the technical feasibility of the method (puncturing or opening of the bile duct and tissue preparation was not necessary), thereby no complications were observed associated with IOUS. IOUS in all cases was performed successfully without an iatrogenic bile duct lesion or other complications.

However, in 5 cases of MRCP motion artifacts were observed, which was the reason of an incomplete interpretation of the imaging data. 


\section{DISCUSSION}

Choledocholithiasis is the main complication of gallstone disease and occurs in 11-21\% of patients during cholecystectomy (Costi, Di Mario and Sarli, 2014). Due to the potentially serious and fatal complications of choledocholithiasis, diagnosis should be made accurately and in time if suspected. Despite the wide range of diagnostic possibilities, the detection of choledocholithiasis is still a major challenge for surgeons and radiologists. As mentioned above, bile duct stones may be predicted by the criteria of preoperative examination; however, the accuracy is not very high (Sherman et al., 2015; Yang et al., 2008). It is important to note that invasive diagnostic methods such as ERCP should not be routinely used in the visualisation of choledocholithiasis. Due to the potentially severe complications of ERCP (Salminen, Laine and Gullichsen, 2008) and costs, the indications for this method are very specific and can only be used for therapeutic purposes in the case of a clear diagnosis. Currently, based on the experience of specialised centres of hepato-pancreato-biliary surgery, ERCP is not recommended as a diagnostic method of complicated gallstone disease. Also, the diagnostic value if IOC is not high, especially in the detection of an iatrogenic lesion. IOC significantly increases the time and costs of the operation. Also, the ionizing radiation that the staff and patients are exposed to is a significant shortcoming (Dili and Bertrand, 2017). In 6-15\% of cases, IOC is associated with diagnostic errors and a lack of information (Catheline, Turner and Paries, 2002).

In many studies MRCP is recommended as the main diagnostic method of complicated gallstone disease (Costi et al., 2014). That is due to the noninvasiveness of the method, its high diagnostic accuracy and the ability to evaluate the biliary system and pancreas before surgery. On the other hand, some reports indicate an incomplete value of MRCP in patients with small 
stones in the bile duct. A recently published comparative study also points to the superiority of IOUS over MRCP in the diagnosis of choledocholithiasis (Ying et al., 2018).

The above-mentioned facts suggest that the optimal diagnostic management of choledocholithiasis is still to be clarified.

\section{Demographics}

The incidence of gallstone disease increases with age, and in 12-20\% of patients over 65 indications for surgical treatment appear (Dua et al., 2014). The overall risk of choledocholithiasis is higher in elderly patients with severe comorbidities (Peker et al., 2014). In this study, the frequency of choledocholithiasis was also more evident in patients with a higher ASA score; patients without comorbidities had a statistically significantly lower incidence of choledocholithiasis. In one of the published reports by Joana Magalhaes, the study population with suspected choledocholithiasis had a mean age of 66.8 years and mainly consisted of women (Magalhaes, Rosa and Cotter, 2015). Similarly, in the present study the median age of patients was 61 years and more than two-thirds of the patients were women $(70.8 \%)$.

\section{Laboratory}

Biochemical markers of the liver (ALT, AST, GGT, AF) may be useful for predicting an incomplete biliary drainage, including due to choledocholithiasis (Czoski-Murray et al., 2012), but there is no evidence of changes in these tests in all cases. Insignificant differences between liver transaminases in patients with and without choledocholithiasis were observed in this study. Reports from literature indicate that no specific imaging is 
required in cases with unchanged liver biochemical parameters and non-dilated bile duct, because choledocholithiasis is not predictable (Yang et al., 2008; Sharara et al., 2010). However, the data of the current study suggest that a significant number of patients may also have stones in a non-dilated bile duct. The direct fraction of bilirubin and the total level of bilirubin were the only statistically significant biochemical indicators that increase in patients with choledocholithiasis. Other authors present similar data, suggesting that only the direct fraction of bilirubin is a very strong predictor of choledocholithiasis and liver transaminases must be estimated very critically (Maple et al., 2010).

\section{Trans-Abdominal Ultrasonography}

TAUS is very important for risk assessment of choledocholithiasis (Maple et al., 2010; Topal et al., 2003; Costi, Sarli et al., 2002); however, the diagnostic value of this method for the detection of choledocholithiasis is low. Nevertheless, other authors and the results of our study suggest the significant role of TAUS in determination of the indirect signs of choledocholithiasis (Isherwood et al., 2014). The most significant indirect sign is the dilatation of the bile duct over $6 \mathrm{~mm}$, although the normal size of the bile duct varies in literature from $5 \mathrm{~mm}$ to $11 \mathrm{~mm}$ (Sarli et al., 2000; Majeed et al., 1999). It mainly depends on a patient's age and compensator extension after cholecystectomy. Bile duct dilatation on TAUS was observed in $71.9 \%$ of patients with proven choledocholithiasis, corresponding to the published data, 55-91 \%, respectively (Liu et al., 2001). Paolo with co-authors (Paolo et al., 1990) reported an increased incidence of choledocholithiasis in patients with a bile duct dilatation over $6 \mathrm{~mm}$ compared to a normal bile duct size. The data of the present study also confirm this thesis (71.9\% versus $44.1 \%)$. It is also reported that the recognition of choledocholithiasis on TAUS is a reliable 
indicator for bile duct stones (Abboud et al., 1996). The current data support this observation, $\mathrm{p}<0.001$. This means that TAUS-verified choledocholithiasis significantly correlates with intraoperative choledocholithiasis, but a negative TAUS finding does not exclude the possibility of stones in the bile duct.

Overall, choledocholithiasis was detected in $13.7 \%$ of all TAUS examinations. Many other authors also point to the insufficient sensitivity of TAUS in detection of choledocholithiasis (Isherwood et al., 2014; Stott et al., 1991). This is explained by the fact that most stones are located in the distal part of the common bile duct and might be covered by gas in the duodenum not permeable by ultrasound. The next reason could be the small size or soft consistency of the stones that do not cause an acoustic shadow.

At the same time, there are reports in literature that in up to half of the patients with choledocholithiasis the bile duct was not dilated after cholecystectomy (Hunt, 1996). The obtained data confirm this observation - in $44.1 \%$ of cases with non-dilated bile duct on TAUS, choledocholithiasis was proved on IOUS during surgery. Thus, it can be concluded, that a non-dilated bile duct or a negative finding on TAUS does not exclude the possibility of choledocholithiasis.

\section{Magnetic Resonance Cholangio-Pancreatography}

Many authors suggest MRCP as a first-line diagnostic method of choledocholithiasis (Hallal et al., 2005; Taylor et al., 2002; Topal et al., 2003; Akisik et al., 2013; Chen et al., 2015). In the existing guidelines (ASGE, 2010), MRCP is also recommended for patients with a medium (10-50\%) risk of choledocholithiasis (Maple et al., 2010; Singhvi et al., 2016). MRCP was used in $23(26.4 \%)$ patients of the medium risk group in the present study. In other $64(73.6 \%)$ patients who were at a high risk for choledocholithiasis, according to the criteria from the ASGE guidelines, choledocholithiasis was not found in 
34. This finding does not comply with the ASGE recommendations to first perform ERCP in high risk patients without any specific diagnostic modality before ERCP. A combined preoperative MRCP and IOUS applied in the selected patient cohort allowed avoidance of unnecessary ERCP and possible complications related to that. There are similar observations published by other authors (Adams et al., 2015; Narvaez-Rivera et al., 2016; Sethi et al., 2016).

According to the data from literature, MRCP has a high diagnostic value in detection of choledocholithiasis (Verma et al., 2006); however, there are reports that indicate an insufficient diagnostic value of MRCP in cases with small stones and sludge in the common bile duct (Ying et al., 2018). The gained data are similar, because the size (median value) of the undiagnosed stones on preoperative MRCP was $3 \mathrm{~mm}$, complying with the data from literature. However, the sensitivity and specificity of MRCP when the stone size was more than $1 \mathrm{~mm}$ reached $82.9 \%$ and $92 \%$, respectively. Despite the discussions about the clinical relevance of bile sludge in the common bile duct, some authors have proved the role of sludge in the pathogenesis of biliary pancreatitis (Santambrogio et al., 1999) and cholangitis (Grier et al., 1994), as well as a high risk of recidivism of biliary pancreatitis in case of undetected microlithiasis - 33-60\%.

It is not possible to detect sludge on $\mathrm{IOH}$ because the contrast agent dilutes small masses and does not show shading on cholangiogram. However, this finding diagnosed on IOUS is important because bile duct flushing can be performed through the cystic duct during surgery by the surgeon. Other authors also report the significant value of IOUS in the detection of sludge compared to other methods (Mirbagheri et al., 2005).

In total, in $139(75.5 \%)$ patients choledocholithiasis was diagnosed on IOUS from all 184 high risk patients (according to the ASGE guidelines), the other $45(24.5 \%)$ patients had no stones in the bile duct. These patients also avoided unnecessary manipulations including ERCP. Unlike MRCP, the 
indications for possible postoperative ERCP are defined very clearly and precisely during surgery on IOUS if clearance of the bile duct fails. In such cases the operation was finished by the formation of cholagiostoma (controlled biliary fistula, mostly trans-cystic for biliary drainage). IOC or postoperative cholangiography with a contrast agent was performed to clarify the condition of the biliary tree and the content of bile ducts according to the indications minimizing unnecessary ERCPs. According to the gained experience, the risk of post-ERCP pancreatitis is reduced in patients with cholangiostoma due to the decompression of the biliary tree, the drainage of the bile and pancreatic juice. Other authors describe a similar experience (Ryan et al., 2014).

\section{Intraoperative Ultrasonography}

IOUS is one of the newest intraoperative imaging methods of choledocholithiasis; it provides the operating surgeon with very precise information of the bile ducts with a very high diagnostic value. IOUS is recommended in the ASGE guidelines in patients with a medium risk of choledocholithiasis (10-50\%) as one of the intraoperative imaging modalities without specific preoperative imaging (Maple et al., 2010). There were $35.9 \%$ medium risk and $62.4 \%$ high risk patients investigated on IOUS. Only 5 patients $(1.7 \%)$ were in the low-risk group; in one of them choledocholithiasis was verified. In all risk groups, the incidence of choledocholithiasis on IOUS matched the recommended values in the guidelines (Maple et al., 2010). Similarly to other authors, the diagnostic value of IOUS in the current study was very high $-99.4 \%$ sensitivity and $94.3 \%$ specificity. The superiority of IOUS over MRCP in the present study is related to the facts that MRCP may miss stones smaller than $<5 \mathrm{~mm}$, especially in patients with biliary pancreatitis (Costi, Gnocchi et al., 2014; Polistina et al., 2015). In contrast, two cases of 
MRCP-verified choledocholithiasis were not confirmed by IOUS during laparoscopy. These two false positive MRCP cases could be explained by the spontaneous transpapillar migration of the gallstone to the duodenum in the time interval between MRCP and surgery. Other authors share a similar experience (Polistina et al., 2015). There are reports presented that in up to a third of patients spontaneous migration of the gallstones to the duodenum before surgery may occur (Tranter and Thompson, 2003), which is much more than in the present study. Therefore, by using IOUS, unnecessary LCBDE and complications related to it can be avoided. The diagnostic value of IOUS in our study population was also superior to MRCP, similarly to the data presented by other authors (Ying et al., 2018).

According to the experience with IOUS of the bile ducts, the possibility to evaluate the permeability of the papilla Vateri. During bile duct rinsing has been recognized; it was also determined that turbulent movements of the fluid in the lumen of the descendent part of the duodenum can be observed.

A careful tissue dissection and a clear recognition of the anatomical structures (bile ducts and blood vessels) are the cornerstones of a safe laparoscopic cholecystectomy. However, in cases of acute inflammation (tissue infiltration) and chronic inflammation (fibrosis), as well as in the case of an atypical/altered anatomy, tissue dissection is complicated. IOUS assists the surgeon, and at any time during the operation may quickly, accurately, safely help to control the anatomy so that patients are not exposed to the risk of an iatrogenic lesion of any structures (Perry, Myers and Deziel, 2008; Dili and Bertrand, 2017). The experience confirms the same; thus, there were no iatrogenic lesions of the bile ducts in patients of the selected study population. 


\section{CONCLUSIONS}

1. Positive IOUS finding was more common in men and in the case of a negative finding, most patients were without co-morbidities.

2. Patients with IOUS approved choledocholithiasis have a higher incidence of mechanical jaundice, cholangitis, higher inflammatory response rates, more frequently pre-operative MRCP was done, whereas biliary pancreatitis was more common in patients with a negative IOUS finding.

3. The diagnostic value of IOUS in the study population is significantly higher than TAUS and is not lower than the diagnostic value of MRCP. IOUS obtained metrics (size of the bile duct and stones) often differed from pre-operative data, as well as biliary sludge and small stones in the common bile duct were often diagnosed by IOUS that were not diagnosed in pre-operative imaging.

4. Diagnostic value of choledocholithiasis of MRCP and IOUS in medium and high-risk groups were the same as published in the ASGE 2010 guidelines; however, the incidence of choledocholithiasis verified with IOUS was higher.

5. IOUS-proven choledocholithiasis has coincided with risk factors such as patient age, cholangitis, mechanical jaundice, biliary dilatation on TAUS and MRCP defined choledocholithiasis. The size of common bile duct determined by MRCP was less important because choledocholithiasis was often diagnosed during surgery by IOUS in patients with not dilated bile duct on pre-operative MRCP.

6. Pre-operative and total hospital stay were reduced for a large group of patients due to IOUS, no iatrogenic lesions of bile ducts were observed, and this method did not significantly prolong the time of operation, that mainly depents from applied LCBDE method. 
7. IOUS has considerable advantages over other diagnostic methods, but the main limitation is the length of time it takes to learn a method and is currently the main factor that discourages surgeons from using this method. 


\section{PRACTICAL RECOMMENDATIONS}

1. IOUS can be used very fast and safely during all phases of laparoscopic cholecystectomy and can be repeated at any time if necessary. IOUS is recommended because:

- it ensures an accurate recognition and localisation of anatomical structures during tissue dissection (risk of a bile duct lesion is reduced);

- it detects the bile duct anatomy and choledocholithiasis in real-time, as well as provides a precise detection of all metrics, which allows applying the most appropriate method for bile duct clearance;

- it allows reducing unnecessary bile duct manipulations during surgery (due to false positive preoperative imaging) and ERCPs;

- possible residual stones after LCBDE can be detected and correction can be performed in time.

2. IOUS can be an alternative for the expensive, time-consuming and insensitive MRCP in case of sludge, leading to a shorter preoperative and total hospital stay.

3. Compared to other imaging methods (TAUS and MRCP), IOUS provides high-precision detection of biliary sludge and stones less than $1 \mathrm{~mm}$, which is not possible to detect by TAUS and MRCP.

4. Additional bile duct imaging is required for all patients with clinically suspected choledocholithiasis even if there is negative finding or not dilated bile duct on TAUS and MRCP. 


\section{BIBLIOGRAPHY}

1. Abboud, P. A., et al. 1996. Predictors of common bile duct stones prior to cholecystectomy: a meta-analysis. Gastrointest Endosc. 44, 450-455.

2. Adams, M. A., et al. 2015. Predicting the likelihood of persistent bile duct stones in patients with suspected choledocholithiasis: accuracy of existing guidelines and the impact of laboratory trends. Gatro-intest Endosc. 82, 88-93.

3. Aerts, R. and Penninckx, F. 2003. The burden of gallstone disease in Europe. Aliment Pharmacol Ther. 18 Suppl 3, 49-53.

4. Akisik, M. F., et al. 2013. MRCP in patient care: a prospective survey of gastroenterologists. Roentgenol. 201 (3), 573-577.

5. ASGE Standards of Practice Committee. Maple, J.T., et al. 2010. The role of endoscopy in the evaluation of suspected choledocholithiasis. Gastrointest Endosc. 71 (1), 1.

6. Banks, P. A., et al. 2013. Acute Pancreatitis Classification Working Group. Classification of acute pancreatitis-2012: revision of the Atlanta classification and definitions by international consensus. Gut. 62 (1), 102.

7. Bencini, L., et al. 2014. Modern approach to cholecysto-choledocholithiasis. World J Gastrointest Endosc. 6 (2), 32-40.

8. Borzellino, G. and Cordiano, C. 2008. Biliary Lithiasis. Basic Science, Current Diagnosis and Management.

9. Catheline, J. M., Turner, R. and Paries, J. 2002. Laparoscopic ultrasonography is a complement to cholangiography for the detection of choledocholithiasis at laparoscopic cholecystectomy. Br J Surg. 89, 1235-1239.

10. Chen, W., et al. 2015. Diagnostic value of magnetic resonance cholangiopancreatography in choledocholithiasis. World J Gastroenterol. 21 (11), 3351-3360.

11. Costi, R., et al. 2014. Diagnosis and management of choledocholithiasis in the golden age of imaging, endoscopy and laparoscopy. World J Gastroenterol. 20 (37), 13382-13401.

12. Costi, R., et al. 2014. Diagnosis and management of choledocholithiasis in the golden age of imaging, endoscopy and laparoscopy. World J Gastroenterol. 20 (37), 13382-13401.

13. Costi, R., Sarli, L., et al. 2002. Preoperative ultrasonographic assessment of the number and size of gallbladder stones: is it a useful predictor of asymptomatic choledochal lithiasis? J Ultrasound Med. 21 (9), 971-976.

14. Czoski-Murray, C., et al. 2012. What is the value of routinely testing full blood count, electrolytes and urea, and pulmonary function tests before elective surgery in patients with no apparent clinical indication and in subgroups of 
patients with common comorbidities: a systematic review of the clinical and costeffective literature. Health Technol Assess. 16, 1-159.

15. Dasari, B. V., et al. 2013. Surgical versus endoscopic treatment of bile duct stones. Cochrane Database Syst Rev. 12, CD003327.

16. Dili and Bertrand. 2017. Laparoscopic ultrasonography as an alternative to intraoperative cholangiography during laparoscopic cholecystectomy. World $J$ Gastroenterol. 23 (29), 5438-5450

17. Dua, A., et al. 2014. National trends in the adoption of laparoscopic cholecystectomy over 7 years in the United States and impact of laparoscopic approaches stratified by age. Minim Invasive Surg. Volume 2014, Hindawi.

18. Grier, J. F., et al. 1994. Acute suppurative cholangitis associated with choledochal sludge. Am J Gastroenterol. 89, 617-619.

19. Hallal, A. H., et al. 2005. Magnetic resonance cholangiopancreatography accurately detects common bile duct stones in resolving gallstone pancreatitis. $J$ Am Coll Surg. 200, 869-875.

20. Hublet, A., et al. 2009. Laparoscopic Ultrasonography as a Good Alternative to Intraoperative Cholangiography (IOC) during Laparoscopic Cholecystectomy: Results of Prospective Study. Acta Chir Belg. 109, 312-316.

21. Hunt, D. R. 1996. Common bile duct stones in non-dilated bile ducts? An ultrasound study. Australas Radiol. 40 (3), 221.

22. Isherwood, J., et al. 2014. Serology and ultrasound for diagnosis of choledocholithiasis. Ann R Coll Surg Engl. 96 (3), 224-228.

23. Kiriyama, S., et al. 2018. Tokyo Guidelines 2018: diagnostic criteria and severity grading of acute cholangitis (with videos). $J$ Hepatobiliary Pancreat Sci. 25, 17-30.

24. Liepins, M. and Lejnieks, A. 2016. Rekomendācijas empīriskai un etiotropai antimikrobiālai ārstēšanai (3. redakcija). Izdevējs SIA "Medikamentu informācijas centrs".

25. Liu, T. H., et al. 2001. Patient evaluation and management with selective use of magnetic resonance cholangiography and endoscopic retrograde cholangiopancreatography before laparoscopic cholecystectomy. Ann Surg. 234, 33-40.

26. Magalhaes, J., Rosa, B. and Cotter, J. 2015. Endoscopic retrograde cholangiopancreatography for suspected choledocholithiasis: From guidelines to clinical practice. World J Gastrointest Endosc. 7 (2), 128-134.

27. Majeed, A. W., et al. 1999. Common duct diameter as an independent predictor of choledocholithiasis: is it useful? Clin Radiol. 54, 170-172.

28. Maple, J. T., et al. 2010. The role of endoscopy in the evaluation of suspected choledocholithiasis. Gastrointest Endosc. 71, 1-8. 
29. Mirbagheri, S. A., et al. 2005. Prospective evaluation of endoscopic ultrasonography in the diagnosis of biliary microlithiasis in patients with normal transabdominal ultrasonography. J Gastrointest Surg. 9, 961-964.

30. Monreal-Robles, R. and Gonzalez-Gonzalez, J.A. 2016. Accuracy of scoring systems for suspected choledocholithiasis: A 5-variable score system versus ASGE clinical guidelines. Surgery. 160 (6), 1715-1716.

31. Narvaez-Rivera, R. M., et al. 2016. Accuracy of ASGE criteria for the prediction of choledocholithiasis. Rev Esp Enferm Dig. 108 (6), 309-314.

32. Nathanson, L. K., et al. 2005. Postoperative ERCP versus laparoscopic choledochotomy for clearance of selected bile duct calculi: a randomized trial. Ann Surg. 242, 188-192.

33. Ong, T. Z., et al. 2005. Complications of endoscopic retrograde cholangiography in the post-MRCP era: a tertiary center experience. World J Gastroenterol. 11, 5209-5212.

34. Paolo, P., et al. 1990. Ultrasonographic diagnosis of choledocholithiasis. Acta Biomed Ateneo Parmense. 61, 213-218.

35. Peker, Y., et al. 2014. Laparoscopic cholecystectomy in patients aged 80 years and older: an analysis of 111 patients. Surg Laparosc Endosc Percutan Tech. 24, 173-176.

36. Perry, K. A., Myers, J.A. and Deziel, D.J. 2008. Laparoscopic ultrasound as the primary method for bile duct imaging during cholecystectomy. Surg Endosc. 22, 208-213.

37. Polistina, F. A., et al. 2015. Accuracy of magnetic resonance cholangiography compared to operative endoscopy in detecting biliary stones, a single center experience and review of literature. World J Radiol. 7 (4), 70-78.

38. Ryan, M. J., et al. 2014. Antegrades wire, rendezvous cannulation of the biliary tree may reduce the incidence of post-ERCP pancreatitis. SAGES.

39. Salminen, P., Laine, S. and Gullichsen, R. 2008. Severe and fatal complications after ERCP: analysis of 2555 procedures in a single experienced center. Surg Endosc. 22 (9), 1965-70.

40. Sankar, A., et al. 2014. Reliability of the American Society of Anesthesiologists physical status scale in clinical practice. Br J Anaesth. 113, 424-432.

41. Santambrogio, R., et al. 1999. Prevalence and laparoscopic ultrasound patterns of choledocholithiasis and biliary sludge during cholecystectomy. Surg Laparosc Endosc Percutan Tech. 9, 129-134.

42. Sarli, L., Costi, R., et al. 2000. Asymptomatic bile duct stones: selection criteria for intravenous cholangiography and/or endoscopic retrograde cholangiography prior to laparoscopic cholecystectomy. Eur J Gastroenterol Hepatol. 12, 11751180 . 
43. Sethi, S., et al. 2016. Prospective assessment of consensus criteria for evaluation of patients with suspected choledocholithiasis. Dig Endosc. 28 (1), 75-82.

44. Sharara, A. I., et al. 2010. Duration of pain is correlated with elevation in liver function tests in patients with symptomatic choledocholithiasis. Clin Gastroenterol Hepatol. 8, 1077-1082.

45. Sherman, J. L., et al. 2015. Validation and improvement of a proposed scoring system to detect retained common bile duct stones in gallstone pancreatitis. Surgery. 157, 1073-1079.

46. Singhvi, G., et al. 2016. ASGE guidelines result in cost-saving in the management of choledocholithiasis. Ann Gastroenterol. 29 (1), 85-90.

47. Stott, M. A., et al. 1991. Ultrasound of the common bile duct in patients undergoing cholecystectomy. J Clin Ultrasound. 19, 73-76.

48. Suarez, A. L., et al. 2016. An assessment of existing risk stratification guidelines for the evaluation of patients with suspected choledocholithiasis. Surg Endosc. 30 (10), 4613-4618.

49. Taylor, A. C., et al. 2002. Prospective assessment of magnetic resonance cholangiopancreatography for noninvasive imaging of the biliary tree. Gastrointest Endosc. 55, 17-22.

50. Topal, B., et al. 2003. The value of magnetic resonance cholangiopancreatography in predicting common bile duct stones in patients with gallstone disease. Br J Surg. 90, 42-47.

51. Tranter, S. E. and Thompson, M. H. 2001. Potential of laparoscopic ultrasonography as an alternative to operative cholangiography in the detection of bile duct stones. Br J Surg. 88, 65-69.

52. Verma, D., et al. 2006. EUS vs MRCP for detection of choledocholithiasis. Gastrointest Endosc. 64 (2), 248.

53. World Medical Association. 2013. World Medical Association Declaration of Helsinki: ethical principles for medical research involving human subjects. JAMA. 310, 2191-2914.

54. Yang, M. H., et al. 2008. Biochemical predictors for absence of common bile duct stones in patients undergoing laparoscopic cholecystectomy. Surg Endosc. $22,1620-1624$.

55. Ying, L., Tao, Y. and Qiang, Y. 2018. Laparoscopic Ultrasonography Versus Magnetic Resonance Cholangiopancreatography in Laparoscopic Surgery for Symptomatic Cholelithiasis and Suspected Common Bile Duct Stones. J Gastrointest Surg. 11605-018-3949-9. 


\section{PUBLICATIONS AND PRESENTATIONS}

\section{Publications of the Study Subject}

- Atstupens, K., Mukans, M., Plaudis, H., Pupelis, G. 2020. The Role of Laparoscopic Ultrasonography in the Evaluation of Suspected Choledocholithiasis. A Single-Center Experience. Medicina 2020, 56(5), 246.

- $\quad$ Atstupens, K., Plaudis, H., Fokins, V., Mukans, M., Pupelis, G. 2016. Safe laparoscopic clearance of the common bile duct in emergently admitted patients with choledocholithiasis and cholangitis. Korean $J$ Hepatobiliary Pancreat Surg. 20: 53-60.

\section{Theses and Presentations at International Congresses}

- Atstupens, K., Fokins, V., Plaudis, H., Pupelis, G. 2019. Laparoscopic intraoperative ultrasonography reduces the need for preoperative MRCP and ERCP in high- and moderate-risk patients with suspected choledocholithiasis. $13^{\text {th }}$ Congress of the EuropeanAfrican Hepato-Pancreato-Biliary Association (E-AHPBA). 2-5 June, Amsterdam, The Netherlands.

- Atstupens, K., Pupelis, G. 2018. Utility of Laparoscopic Ultrasound in One-step Management of Suspected Choledocholithiasis. Learning Curve Based on 4 Years Experience. 13 ${ }^{\text {th }}$ World Congress of the International Hepato-Pancreato-Biliary Association. 4-7 September, Geneva, Switzerland.

- Plaudis, H., Saukane, E., Atstupens, K., Fokin, V., Pupelis, G. 2018. Laparoscopic common bile duct exploration for bile duct stones. $13^{\text {th }}$ World Congress of the International Hepato-Pancreato-Biliary Association. 4-7 September, Geneva, Switzerland.

- Atstupens, K., Pupelis, G. 2017. The Role of Intraoperative Ultrasonography in the Verification of Choledocholithiasis. $12^{\text {th }}$ International Congress of the European-African Hepato-PancreatoBiliary Association. 23-26 May, Mainz, Germany. 
- Atstupens, K., Mukans, M., Plaudis, H., Pupelis, G. 2016. Intraoperative ultrasound compared to magnetic resonance cholangiopancreatography in patients with suspected choledocholithiasis. $12^{\text {th }}$ World Congress of the International HepatoPancreato-Biliary Association. 20-23 April, Sao Paulo, Brazil.

- $\quad$ Atstupens, K., Plaudis, H., Saukane, E., Fokins, V., Pupelis, G. 2016. Laparoscopic one-stage management of patients with suspected choledocholithiasis. A 3-year experience in single institution. $12^{\text {th }}$ World Congress of the International Hepato-Pancreato-Biliary Association. 20-23 April, Sao Paulo, Brazil.

- Atstupens, K., Plaudis, H., Mukans, M., Pupelis, G. 2015. Laparoscopic intraoperative sonoscopy and choledochoscopy in patients with suspected choledocholythiasis. $8^{\text {th }}$ Congress of the Baltic Association of Surgeons. 10-12 September, Tallinn, Estonia.

- $\quad$ Atstupens, K., Fokins, V., Plaudis, H., Mukans, M., Pupelis, G. 2014. Laparoscopic intraoperative ultrasonoscopy in patients with choledocholithiasis. $11^{\text {th }}$ World Congress of the International HepatoPancreato-Biliary Association. 22-27 March, Seoul, Korea.

- Plaudis, H., Melberga, L., Kazaka, I., Atstupens, K., Fokin, V., Mukans, M., Pupelis, G. 2014. Urgent one stage laparoscopic intraoperative sonoscopy and choledochoscopy in patients with suspected choledocholythiasis. $11^{\text {th }}$ World Congress of the International Hepato-Pancreato-Biliary Association. 22-27 March, Seoul, Korea.

- $\quad$ Plaudis, H., Fokins, V., Kaminskis, A., Melberga, L., Atstupens, K., Kazaka, I., Mukans, M., Pupelis, G. 2013. Laparoscopic common bile duct exploration is safe alternative to preoperative endoscopic clearance of the common bile duct. International Surgical Week. 2529 August, Helsinki, Finland. 